\title{
Seasonal and predator-prey effects on circadian activity of free-ranging mammals revealed by camera traps
}

Anthony Caravaggi ${ }^{\text {Corresp., }}{ }^{1,2}$ ， Maria Gatta ${ }^{3}$, Marie-Claire Vallely ${ }^{1,4}$, Kayleigh $\operatorname{Hogg}^{1}$, Marianne Freeman ${ }^{1}$ Erfan Fadaei $^{1,5}$, Jaimie TA Dick ${ }^{1,5}$ ，W. Ian Montgomery ${ }^{1,5}$, Neil Reid ${ }^{1,5}$, David G Tosh ${ }^{1,6}$

${ }^{1}$ School of Biological Sciences, Queen's University Belfast, United Kingdom

2 School of Biological Earth and Environmental Sciences, University College Cork, Cork, Ireland

3 School or Animal, Plant and Environmental Sciences, University of Witwatersrand, South Africa

${ }^{4}$ Northern Ireland Environment Agency, United Kingdom

5 Institute of Global Food Security (IGFS), Queen's University Belfast, United Kingdom

${ }^{6}$ National Museums of Northern Ireland, United Kingdom

Corresponding Author: Anthony Caravaggi

Email address: ar.caravaggi@gmail.com

Endogenous circadian and seasonal activity patterns are adapted to facilitate effective utilisation of environmental resources. Activity patterns are shaped by physiological constraints, evolutionary history, circadian and seasonal changes and may be influenced by other factors, including ecological competition and interspecific interactions. Remote sensing camera traps allow the collection of species presence data throughout the 24-hour period, and for almost indefinite periods. Here, we collate data from ten separate camera trap surveys in order to describe circadian and seasonal activity patterns of ten mammal species, and, in particular, to evaluate interspecific (dis)associations of five predator-prey pairs. We recorded 8,761 independent detections throughout Northern Ireland. Badgers, foxes, pine martens and wood mice were nocturnal; European and Irish hares and European rabbits were crepuscular; fallow deer and grey and red squirrels were diurnal. All species exhibited significant seasonal variation in activity relative to the timing of sunrise/sunset. Foxes in particular, were more crepuscular from spring to autumn and hares more diurnal. Lagged regression analyses of predator-prey activity patterns between foxes and prey (hares, rabbits and wood mice), and pine marten and prey (squirrel and wood mice) revealed significant annual and seasonal cross-correlations. We found synchronised activity patterns between foxes and hares, rabbits and wood mice and pine marten and wood mice, and asynchrony between squirrels and pine martens. Here, we provide fundamental ecological data on endemic, invasive, pest and commercially valuable species in Ireland, as well as those of conservation importance and those that could harbour diseases of economic and/or zoonotic relevance. Our data will be valuable in informing the development of appropriate species-specific methodologies and processes and associated policies. 
1 Original Article

2 Seasonal and predator-prey effects on circadian activity of free-ranging mammals revealed 3 by camera traps

4 Anthony Caravaggi 1,2*, Maria Gatta ${ }^{3}$, Marie-Claire Vallely ${ }^{1,4}$, Kayleigh Hogg ${ }^{5}$, Marianne 5 Freeman $^{1}$, Erfan Fadaei1,5, Jaimie T.A. Dick ${ }^{1,5}$, W. Ian Montgomery ${ }^{1,5}$, Neil Reid ${ }^{1,5}$, David G $6 \operatorname{Tosh}^{1,6}$

7

$8{ }^{1}$ School of Biological Sciences, Queen's University Belfast, Belfast, BT9 7BL, UK.

$9{ }^{2}$ School of Biological Earth and Environmental Sciences, University College Cork, Distillery 10 Field, North Mall, Cork, Ireland.

113 School of Animal, Plant and Environmental Sciences, University of the Witwatersrand, 12 Johannesburg, South Africa

134 Northern Ireland Environment Agency, Klondyke Building, Cromac Avenue, Gasworks 14 Business Park, Belfast, BT7 2JA

155 Institute of Global Food Security (IGFS), Queen's University Belfast, Belfast, BT9 5BN, UK.

${ }^{6}$ National Museums of Northern Ireland, 153 Bangor Road, Holywood, Co Down, BT18 0EU.

17

* Corresponding author: ar.caravaggi@gmail.com

19

Word count: 6,695 (excluding references) 
23 Abstract

24

Endogenous circadian and seasonal activity patterns are adapted to facilitate effective utilisation

of environmental resources. Activity patterns are shaped by physiological constraints, evolutionary

27 history, circadian and seasonal changes and may be influenced by other factors, including ecological competition and interspecific interactions. Remote sensing camera traps allow the collection of species presence data throughout the 24-hour period, and for almost indefinite periods. Here, we collate data from ten separate camera trap surveys in order to describe circadian and seasonal activity patterns of ten mammal species, and, in particular, to evaluate interspecific (dis)associations of five predator-prey pairs. We recorded 8,761 independent detections throughout Northern Ireland. Badgers, foxes, pine martens and wood mice were nocturnal; European and Irish hares and European rabbits were crepuscular; fallow deer and grey and red squirrels were diurnal. All species exhibited significant seasonal variation in activity relative to the timing of sunrise/sunset. Foxes in particular, were more crepuscular from spring to autumn and hares more diurnal. Lagged regression analyses of predator-prey activity patterns between foxes and prey (hares, rabbits and wood mice), and pine marten and prey (squirrel and wood mice) revealed significant annual and seasonal cross-correlations. We found synchronised activity patterns between foxes and hares, rabbits and wood mice and pine marten and wood mice, and asynchrony between squirrels and pine martens. Here, we provide fundamental ecological data on endemic, invasive, pest and commercially valuable species in Ireland, as well as those of conservation importance and those that could harbour diseases of economic and/or zoonotic relevance. Our data will be valuable in informing the development of appropriate species-specific methodologies and processes and associated policies. 
48

49

\section{Introduction}

Animal activity patterns are influenced by a variety of environmental pressures, including food availability (Larivière et al., 1994, Pereira, 2010), foraging efficiency (Lode, 1995; Prugh \& Golden, 2014), predator/prey activity (Fenn \& McDonald, 1995; Middleton et al., 2013), human disturbance (van Doormaal et al., 2015; Wang et al., 2015), mate availability and activity (Thompson et al., 1989; Halle \& Stenseth, 2000), and ecological competition (Rychlik, 2005; Montorroso et al., 2014). Mammals exhibit a great diversity and flexibility in their activity patterns. A recent study of 4,477 mammal species classified $69 \%$ as nocturnal (i.e. night-active), $20 \%$ diurnal (i.e. day-active), $8.5 \%$ cathemeral (i.e. active throughout the 24 -hour cycle) and $2.5 \%$ crepuscular (i.e. dawn- and/or dusk-active, e.g. lesser mouse deer; Bennie et al., 2014). Circadian (i.e. recurring every 24 hours) and seasonal patterns of activity are adaptive behavioural traits which allow species to effectively exploit their environment and the resources contained therein (Phillips et al., 2013).

Activity patterns evolved in response to cyclical changes in the environment that encouraged organisms to respond on a physiological and behavioural basis (Daan, 1981, KronfeldSchor \& Dayan, 2003; Roll et al. 2006; Bennie et al., 2014). Activity patterns are frequently related to daily oscillation in illumination (e.g. changes in sunrise/sunset; Halle \& Stenseth, 2000) and, hence, the time(s) of the day during which species are active may vary according to season (i.e. spring, summer, autumn, and winter). Indeed, it has been suggested that photic cues are the dominant factor underlying behavioural rhythmicity and that a species' potential to adapt to nonphotic cues (e.g. ecological competitors, predators) may be constrained such that responses are manifest within the normal active period rather than as a shift to a different rhythm (KronfeldSchor \& Dayan, 2003). The capacity for adaptive behavioural plasticity, while limited in some 
species (Kronfeld-Schor \& Dayan, 2003), is demonstrated in others by observations of intraspecific variation of activity patterns (e.g. Ashby, 1972, Herte et al., 2017) that can result in temporal niche switching (Fenn \& McDonald, 1995; Ensing et al., 2014). For example, Ensing et al. (2014) found that red deer (Cervus elaphus) were mostly diurnal in Canada, while conspecifics in the Netherlands were mostly nocturnal. The difference in activity patterns was attributed to higher levels of human disturbance and a lack of natural predators in the Netherlands.

The island of Ireland has a depauperate terrestrial mammalian community due to its prolonged isolation since the last Glacial Maximum (Montgomery et al., 2014). The behavioural ecologies of mammals in Ireland are almost entirely unknown and assumptions of behavioural equivalence between Ireland and locations elsewhere in the species' range may not apply given differences in land use, human activity and ecosystem composition. Quantifying fundamental ecological parameters such as activity patterns has direct relevance to the management of endemic (e.g. Irish hare, Lepus timidus hibernicus; Reid \& Montgomery, 2007), invasive (e.g. European hares, Lepus europaeus; Caravaggi et al., 2015), pest (e.g. foxes; Baker \& Harris, 2006) and commercially valuable (e.g. deer; Carden et al., 2011) species, as well as those that could harbour diseases of economic (e.g. badgers, Meles meles; Griffin et al, 2005) and/or zoonotic relevance. The relative dearth of mammalian herbivores and their predators in Ireland also makes the island an ideal study system in which to investigate predator-prey relationships. However, recording and quantifying daily activity patterns of wild, free-ranging mammals presents significant challenges, including overcoming the observer effect whereby the presence of an observer influences the behaviour of the subject (Stewart et al., 1997), and collecting sufficient data to address scientific and conservation questions (sensu Cagnacci et al., 2010). A number of methodological techniques have been used to overcome such challenges such as radio-tracking, GPS collars and live trapping, 
92 each with varying degrees of success (Bridges \& Noss, 2011). Radio-tracking has inherent

93 limitations, including periodic (i.e. non-constant) sampling (e.g. Lovari et al., 1994) and the

94 application of considerable survey effort (Palomares \& Delibes, 1991; Reid, McDonald \&

95 Montgomery, 2010). Furthermore, they may result in small sample sizes (Bridges \& Noss, 2011),

96 capture a limited proportion of the population (Sadlier et al., 2004), and may be subject to signal-

97 based error and/or omission (Cagnacci et al., 2010) or alter the behaviour of tagged animals (e.g.

98 Wilson et al., 2011). GPS collars have similar constraints to radio-tracking, particularly with

99 regards to sample sizes and potential signal issues. Moreover, inferences made from GPS collar

100 data can lead to misleading results and much depends on the frequency with which location fixes

101 are obtained (Merrill \& Mech 2003). Live trapping has been used to investigate activity patterns

102 of small mammals, where each successful capture (i.e. the presence of an animal in a trap) is taken

103 as indicating activity (e.g. Elton et al., 1931; Bradley, 1967; Hoogenboom et al., 1984). However,

104 live trapping requires considerable time and effort, is relatively inefficient, may have implications

105 with regards to animal welfare (Torre et al., 2010), and is subject to species- and trap-specific

106 variations in capture probability (Leso \& Kropil, 2010).

Remote-sensing camera traps (i.e. remotely activated cameras that are activated via motion

or infra-red sensors or light beams) are increasingly popular in conservation and ecological studies

110 costs (Tobler et al., 2008a). They have been used in studies investigating population densities (e.g.

111 Trolle \& Kéry, 2003, Karanth et al., 2006, Caravaggi et al., 2016), behaviour (e.g. Maffei et al.,

112 2005), ecosystem biodiversity (e.g. Silveira et al., 2003, Tobler et al., 2008b), and site occupancy

113 of rare or cryptic species (e.g. Linkie et al., 2007). Camera traps afford researchers the means to

114 conduct long-term surveys while minimising in-situ survey effort and disturbance of the focal 
115 species (Kays \& Slauson, 2008). As such, data derived from camera trap surveys of common

116 species and/or conducted at high camera densities are well suited to investigations of wildlife

117 activity patterns (e.g. Di Cerbo \& Biancardi, 2013, Carbajal-Borges et al., 2014; Allen et al., 2018).

118 The size and scope of camera trap surveys are limited only by the cost of equipment and personnel

119 to conduct fieldwork and review and analyse data, while the length of time cameras can be left in-

120 situ is restricted by available memory, battery life and the possibility of mechanical failure. There

121 may be a trade-off between the proximity and angle of cameras with regards to targets, and the

122 likelihood of detecting and identifying species of varying size (Hofmeester et al., 2017).

123 Downward-facing cameras, for example, are more efficient at detecting small mammals, (De

124 Bondi et al., 2010). However, species identification is difficult where similar species occur in

125 sympatry (Claridge et al., 2010; Meek et al., 2013; Oliveira- Santos et al., 2010). This is often

126 particularly true of small mammals (e.g. Claridge et al., 2010; Meek \& Vernes, 2016). However,

127 Ireland is home to six species of rodent and two species of shrew, few of which occur in sympatry

128 and all of which are uniquely identifiable.

Here, we describe the first study into temporal activity patterns of ten mammal species found in Ireland, from $14 \mathrm{~g}$ (wood mouse) to $60 \mathrm{~kg}$ (fallow deer), captured via camera traps. In addition, we investigate interspecific relationships, specifically whether predator-prey activity patterns demonstrate (a)synchrony, demonstrating temporal (dis)association between ecologically-

133 linked species. We hypothesised that predator-prey pairs would exhibit non-random, interrelated 134 distribution of activity throughout the diel cycle. This distribution would either display a 135 considerable overlap between predators and prey (i.e. predators are attracted to prey), or 136 asynchrony between the species (i.e. temporal avoidance of predators by prey). 


\section{Materials and methods}

138 We collated data from 10 camera trap studies conducted in Northern Ireland, where land use is 139 predominantly agricultural (75\%) and forest cover, mixed and deciduous woodland and coniferous

140 forest plantations, is 8\% of land area (Department of Agriculture, Environment and Rural Affairs, 141 2018; Forestry Comission, 2018). The focal species of the 10 studies were fallow deer (Dama 142 dama, Linnaeus 1758; n=6), Eurasian red squirrel (Sciurus vulgaris, Linnaeus 1758) and Eastern 143 North American grey squirrel (S. carolinensis, Gmelin 1788; n=2) and European brown hare 144 (Lepus europeaus, Pallas 1778) and Irish mountain hare (L. timidus hibernicus, Bell 1837; n=2). 145 However, as is common for camera trap studies, non-target species were also detected. Therefore, 146 in addition to the 5 focal species, we present additional information on a further 5 species: i) 147 European badger (Meles meles, Linnaeus 1758); ii) European rabbit (Oryctolagus cuniculus, 148 Linnaeus 1758); iii) wood mouse (Apodemus sylvaticus, Linnaeus 1758); iv) pine marten (Martes 149 martes, Linneus 1758); and v) red fox (Vulpes vulpes, Linnaeus 1758; hereafter 'fox'). The data 150 presented here resulted from a total of 1,164 camera deployments at 431 locations (defined herein 151 as broad study areas, rather than individual camera placements; Fig. 1). Deer surveys were 152 conducted from June 2013 to November 2016, squirrel surveys from January to March in 2014 153 and January to May in 2015 and hare surveys from April 2013 to August 2015, non-inclusive. 154 Constituent surveys were independent and, hence, methodologies were not standardised. There 155 was no evidence of intrageneric variation in the activity patterns of hare (Fig. S1) and squirrel (Fig. 156 S2) species, and, hence, both were grouped (i.e. 'hares' and 'squirrels') for the purposes of the 157 current study. 
160 We included data from six independent deer studies (D1 - 6) in our analyses. D1 and 2 were 161 conducted over $151 \mathrm{~km}^{2}$ squares with an average of 10 cameras per $\mathrm{km}^{2}$ and 5 additional $1 \mathrm{~km}^{2}$ 162 squares set at a higher density of 20 camera traps per $\mathrm{km}^{2}$. In total 38 camera trap units were randomly deployed over 255 individual camera trap placements (Table 1) using a combination of Bushnell Trophy Cam (119467), Bushnell Trophy Cam HD (119477), Reconyx (HC600) and Scoutguard Camera (SG560P-8M) - the number of each model used differed between sites. Camera traps were set at a height of $30 \mathrm{~cm}$, perpendicular to the ground. Cameras were set to capture the maximum photographs per trigger (3-10 photographs depending on camera model) and no delay between triggers. Cameras were left for 14 days before being collected and relocated. D3 surveyed smaller areas of $0.05 \mathrm{~km}^{2}, 0.02 \mathrm{~km}^{2}$ and $0.04 \mathrm{~km}^{2}$ using ten Bushnell Trophy Cam HD (119677) at each site. Each camera was set at a height of $40 \mathrm{~cm}$ from the ground and set to capture bursts of 3 still pictures and a 60-second video per trigger, with a delay of one second

172 between triggers. Cameras were left in situ for 7 days. D4 was focussed on areas of $0.05 \mathrm{~km}^{2}$ and $1730.02 \mathrm{~km}^{2}$ and used Bushnell Trophy Cam HDs (119477, 119577, 119676, 119677). Cameras were set at a height of $40 \mathrm{~cm}$ and set to capture either 3 still pictures or a 30 s video, depending on the camera model, with a one second delay between triggers. Cameras were deployed for 7 days. twenty-three $1 \mathrm{~km}^{2}$ squares. Each square contained twenty randomly placed Bushnell Trophy Cam

178 HD (119477) camera traps that were positioned on vertical aspects of linear features (i.e. trees in 179 hedgerows, fence posts), to a total of 460 camera locations (Table 1). Cameras were set at a height 180 of $30 \mathrm{~cm}$ from the ground, at a $45^{\circ}-90^{\circ}$ angle away from the linear feature, with a $10-15^{\circ}$ 181 downward tilt. Cameras were set to record video for a period of 60 seconds with a 60 second delay 
182 between triggers. Cameras were deployed for 7 days. The use of video footage allowed the 183 detection of closely-associated conspecifics (see Caravaggi et al., 2016 for more on this study).

184

185

186

187

188

189

190

191

192

193

194

196

197

198

199

200

201

202

203

204
Data from two arboreal squirrel surveys are presented in this study. The first survey (S1) was undertaken in 2014, within 63 forested areas $>5$ ha in size within Co. Fermanagh. A total of 16 Bushnell Trophy Cameras (119438) were deployed by 7 volunteers ('citizen scientists') and 1 scientist during a 3-month period (Table 1). Cameras were attached to trees at a height of 3-4m and positioned up to $4 \mathrm{~m}$ distant from and opposite a wooden squirrel feeder (Northumbrian Wildlife Trust design) baited with peanuts and sunflower seeds. Cameras were left in situ for a minimum of 7 and maximum of 24 days (median $=8$ ). The second survey (S2) was conducted in 314 forested areas $>5$ ha in size across Northern Ireland by 70 citizen scientists and 1 scientist during a 5-month period in 2015. A total of 65 Bushnell Trophy Cameras (16 x 119438; 12 x 119577; 37 x 119676) were deployed during this time for a minimum of 6 and maximum of 33 days (median $=7)$. Cameras were deployed at head height $(1.5-2 \mathrm{~m})$ on a tree opposite either a wooden (as in 2014) or metal squirrel feeder (CJ Wildlife Product code 12335). In both years, cameras were set to take 3 photos per burst with an interval of $1-20$ seconds between triggers. In these surveys all citizen scientists were trained in the use of camera traps by the scientist (DT) overseeing the research.

In deer and hare surveys, cameras were placed according to $n_{i}$ randomly generated points within each focal area and a clear field of view was ensured by clearing prominent vegetation where appropriate. The density of deployed camera trap arrays means that it was possible that the same individual would be captured more than once during the sampling period. Similarly, cameras were pseudo-randomly placed during squirrel surveys according to suitably paired trees (one for the camera, one for the feeder) of which there were an abundance in all locations. Recaptures were 
205 highly likely given the use of baited stations. Surveys with $>1$ camera trap model did not

206 systematically deploy models predictably within and across arrays. In all surveys, cameras were

207 equipped with fitted with 8 GB HDSD cards, secured with Python security cables, motion detectors

208 were set to medium sensitivity and each capture was stamped with the date and time.

Activity analysis

We assumed that images were independent when separated by one hour (e.g. Cusack et al., 2015) and that temporal detection frequency was a true reflection of circadian activity patterns of the focal species. Animals can only be detected on camera traps only when active, specifically, when in motion. The number of detections per hour therefore reflects the level of activity across the circadian period. Prior to analysis, data for individual species were grouped into one-hour time intervals, beginning at the hour mark (e.g. 11:00 - 11:59). . In cases where a group of individuals of the same species (e.g. fallow deer) was detected in one image, a single event was recorded.

Detection frequencies were normalised to ease plot interpretation using the formula $z_{i}=\frac{x_{i}-x_{\min }}{x_{\max }-x_{\min }}$ 219 , where $z_{i}=$ normalised detection frequency at the $i$ th interval, and $x=\left(x_{1} \ldots, x_{n}\right)$. example, an ostensibly nocturnal species may be more likely to remain active into daylight hours

222 during the summer months due to shortening nights to meet its energetic requirements (SchaiBraun et al., 2012). To investigate intra-annual variation in activity relative to sunrise/sunset (i.e. whether nocturnal/diurnal activity differed between seasons; solar cycle historical data obtained 225 from the HM Nautical Almanac Office, 2016), data were grouped according to season: spring 226 (March - May); summer (June - August); autumn (September - November); and winter 
227 (December - February). Detections between 00:00 and 11:59 were offset relative to sunrise;

228 detections between 12:00 and 23:59 were offset relative to sunset. All daytime offsets were

229 converted to positive integers, night-time to negative. For example, a detection timed at 22:10,

230 with sunset at 20:00, would have an offset value of -2 hours and 10 minutes, indicating nocturnal

231 activity. We investigated intraspecific differences in seasonal offsets via one-way Analysis of

232 Variance (ANOVAs) with post-hoc Tukey tests where the dependent variable was the

233 sunrise/sunset offset, and season was the explanatory variable.

We defined the diurnal period as the time between one hour after sunrise and one hour

before sunset, and the nocturnal period as the time between one hour before sunrise and one hour after sunset. We defined the crepuscular periods, dawn and dusk, as the hour before and the hour after sunrise and sunset respectively (after Theuerkauf et al., 2003; Ross et al., 2013). Species activity patterns were classified according to the diel period with the most activity.

We used overlap metrics and lagged regression cross-correlation functions (CCFs) to examine annual and seasonal relationships between predator-prey pairs (i.e. autocorrelation), specifically: fox and hare; fox and rabbit; fox and wood mouse; pine marten and squirrel; and pine marten and wood mouse. These relationships were explored due to dietary studies indicating the potential for predator-prey dynamics within the $24 \mathrm{hr}$ period. Lagomorphs are primary prey items of the red fox in Ireland (e.g. Fairley, 1970). In Britain the field vole (Microtus agrestis) is a secondary prey item for the red fox (Webbon et al., 2006) and primary item for the pine marten

246 (Caryl et al., 2012) but this species does not occur in NI where the wood mouse is the most 247 abundant small mammal species (Twinning et al., 2018). Data used to examine predator prey 248 relationships were restricted to locations where both species in each pair were detected. Sample 249 CCFs facilitate the identification of lags in the $x$ variable which may be predictive of $y$. Positive 
$250 \operatorname{lag}(h+)$ is the result of a correlation between $x_{a+i}$ and $y_{a}$, where $a=$ time. Conversely, negative lag

$251(h-)$ is the result of a correlation between $x_{a-i}$ and $y_{a}$. Significant correlations describe a non-random

252 association between species detections at interval(s) $h_{i}$. Lagged regressions were calculated using

253 the ccf function in the core library of R (R Core Team 2016). The CCF function, however, does

254 not return quantified measures of significance. The significance of the correlation coefficient, $r$,

255 therefore, was established by calculating the $t$ value, where $t=r \sqrt{\frac{n-2}{1-r^{2}}}$ and where the critical $t$

256 value $(p=0.05,22$ degrees of freedom, one-tailed $)=1.72$. We calculated the degree of overlap

257 between each species pair on an annual basis and for each season using the overlap package

258 (Meredith \& Ridout, 2017). Data were resampled 1,000 times per pair, per category, to generate

259 95\% Confidence Intervals (CI). We defined overlap $<0.5$ as low overlap, 0.5-0.75 as moderate

260 overlap, and $>0.75$ as high overlap (Monterroso et al., 2014). All statistical analyses were carried

261 out in R 3.4.3 (R Core Team, 2017; see Caravaggi et al., 2018, for data and code). 


\section{Results}

264 A total of 8,761 independent detections of the ten species were recorded across 324 camera days. 265 Squirrel sightings $(n=2,870$; Fig. $2 \mathrm{~g})$ comprised $33 \%$ of all records, rabbits $13 \%(n=1,175$; Fig. 266 2f), pine martens 11\% $(n=966$; Fig. 2e), badgers $11 \%(n=947$; Fig. 2a $)$, wood mice 9\% $(n=816$; 267 Fig. $2 \mathrm{~h})$, hares 9\% $(n=751$; Fig. 2d), foxes 7\% $(n=645$; Fig. 2 d $)$, and fallow deer $7 \%(n=591$;

268 Fig. 2b; Table 2). Seasonal variations in the number of detections recorded reflected the time and 269 duration of the constituent studies: $47 \%$ in spring, $24 \%$ in summer, $18 \%$ in autumn, and $11 \%$ in 270 winter (Table 2).

\section{Species-specific activity patterns} three-quarters of all fox activity (73\%) occurred between 21:00-07:00 (Fig. 3a). Pine marten activity was nocturnal, with 70\% of all detections occurring between 21:00 and 06:00 (Fig. 3b). Badgers were nocturnal with a unimodal pattern of activity; the number of detections increased rapidly after dusk and decreased rapidly around dawn. Fewer than $15 \%$ of all badger detections were recorded between 06:00-19:00, indicating little diurnal activity (Fig. 3c). Hare activity patterns were bimodal, demonstrating predominantly crepuscular behaviour with $71 \%$ of all activity occurring between 04:00-08:00 (47\%) and 20:00-23:00 (24\%; Fig. 3a). Rabbits were also crepuscular, with $35 \%$ and $32 \%$ of all detections occurring between 04:00-08:00 and 17:00-23:00, respectively (Fig. 3a). Squirrels were diurnal, being active from dawn to dusk with fewer than 5\% of triggers occurred between 19:00 and 05:00 (Fig. 3b). Wood mice were nocturnal with 81\% of 
284 activity occurring between 21:00 and 06:00 (Fig. 3b). Overall, fallow deer were diurnal with 63\%

285 of detections occurring between 06:00 and 18:00 (Fig. 3c)

286

There were significant differences in offsets across seasons in fox activity patterns $\left(\mathrm{F}_{33,641}\right.$

$287=23.36, \mathrm{p}<0.0001)$; winter was significantly different from all other seasons due to decreased

288 activity during daylight and crepuscular periods (Fig. 4c). Significant differences were observed

289 across and between all seasons $\left(\mathrm{F}_{3,962}=86.28, \mathrm{p}<0.0001\right)$, except spring-autumn in pine marten

290 activity patterns (Fig. 4b). Badger activity patterns exhibited significant differences in offsets

291 across seasons $\left(\mathrm{F}_{3,943}=32.54, \mathrm{p}<0.0001\right.$; Fig. 4c $)$ except for winter-autumn and summer-spring.

292 Seasonal offsets differed significantly in hare activity patterns $\left(\mathrm{F}_{3,747}=19.33, \mathrm{p}<0.0001\right)$,

293 specifically between spring and summer $(\mathrm{p}<0.0001)$ and summer and autumn $(\mathrm{p}<0.001$; Fig.

294 4d); hares exhibited more diurnal activity both in spring and in autumn. There were significant

295 differences in offsets across and between seasons in rabbit $\left(F_{3,1171}=12.93, p<0.0001 ;\right.$ Fig. $\left.4 f\right)$ and

296 squirrel activity patterns $\left(\mathrm{F}_{3,2866}=76.52, \mathrm{p}<0.0001\right.$; Fig. 4g). Fallow deer activity patterns

297 exhibited significant differences in offsets across seasons $\left(F_{3,587}=16.7, p<0.0001\right)$, specifically

298 between spring and autumn $(\mathrm{p}<0.0001)$ and summer and autumn $(\mathrm{p}>0.0001$; Fig.4b). Offsets

299 were significantly different across seasons in wood mouse activity patterns $\left(\mathrm{F}_{3,812}=39.31, \mathrm{p}<\right.$ 300 0.0001), with diurnal activity increasing in summer (Fig. 4h).

301

302

\section{Predator-prey relationships}

303 There was evidence of correlative relationships between all predator-prey pairs both annually and

304 between seasons. Fox and hare annual activity patterns showed 73\% overlap (CI 68\% - 77\%; Table

305 3) and were significantly positively correlated with a peak at $-2 \mathrm{hrs}$ (peak lag $=p l$, hereafter; 
$306 \mathrm{r}=0.663, \mathrm{t}_{22}=4.15, \mathrm{p}<0.0005$, Table 4$)$. The degree of overlap peaked in spring at $75 \%$ (CI $64 \%$ -

30784 , Table 3; $p l=1 \mathrm{hr}, \mathrm{r}=-0.554, \mathrm{t}_{22}=3.12, \mathrm{p}<0.005$, Table 4). There were significant correlations

308 in the summer (Table 4).Annual activity patterns of foxes and rabbits overlapped by $80 \%$ (CI 75\%

$309-83 \%$, Table 3$)$ and were significantly correlated, with a peak at $-1 \mathrm{hr}\left(p l=-1 \mathrm{hr}, \mathrm{r}=0.661, \mathrm{t}_{22}=\right.$

$3104.13, \mathrm{p}<0.0005$, Table 4). Overlap was greatest during spring at $89 \%$ (CI 86\% - 98\%, Table 3;

$311 p l=1 \mathrm{hr}, \mathrm{r}=0.701, \mathrm{t}_{22}=4.61, \mathrm{p}<0.0005$, Table 4$)$ and lowest during winter $(51 \%$, CI $31 \%-71 \%$,

312 Table 3). Seasonal activity patterns between foxes and rabbits were positively correlated during

313 spring and summer (Table 4), but there were no significant correlations evident during the rest of

314 the year. Fox and wood mouse annual activity patterns overlapped by $81 \%$ (CI $75 \%-87 \%$; Table

315 3). Overlap was high in all seasons but was greatest in summer with at $85 \%$ (CI $81 \%-92 \%$, Table

316 3). Annual activity was significantly correlated $\left(p l=1 \mathrm{hr}, \mathrm{r}=0.754, \mathrm{t}_{22}=5.39, \mathrm{p} \leq 0.0001\right.$, Table 4),

317 with similar peaks in cross-correlation coefficients in spring (Table 4) and autumn, with greatest

318 correlation occurring in summer $\left(p l=0 \mathrm{hrs}, \mathrm{r}=0.761, \mathrm{t}_{22}=5.50, \mathrm{p} \leq 0.0001\right.$, Fig Table 4$)$.

Pine marten and wood mouse annual activity patterns were correlated with a $71 \%$ (CI 64\%-

$74 \%$ ) overlap $\left(p l=0 \mathrm{hrs}, \mathrm{r}=0.536, \mathrm{t}_{22}=2.98, \mathrm{p} \leq 0.05\right.$, Table 4$)$. Overlap was greater than $50 \%$ for

all seasons with a peak of 77\% (CI 66\%-93\%) occurring in winter months (Table 3). Activity

322 patterns were significantly correlated in spring ( $p l=10 \mathrm{hrs}, \mathrm{r}=-0.44, \mathrm{t}_{22}=2.29, \mathrm{p} \leq 0.05$, Table 4) and winter $\left(p l=3 \mathrm{hrs}, \mathrm{r}=-0.503, \mathrm{t}_{22}=2.73, \mathrm{p} \leq 0.05\right)$. Pine marten and squirrel annual patterns overlapped by $40 \%$ (CI 33\% - 41\%, Table 3 ) and their activity was significantly correlated $(p l=$ $2 \mathrm{hrs}, \mathrm{r}=-0.621, \mathrm{t}_{22}=3.72, \mathrm{p}<0.001$; Table 4 ). Seasonal overlap peaked during summer at $54 \%$ (CI 41\% - 60\%) but was almost entirely absent during winter (Table 3). Significant correlations 
$328=1 \mathrm{hr},\left(\mathrm{r}=-0.625, \mathrm{t}_{22}=3.76, \mathrm{p}>0.001\right)$; summer, $p l=-2 \mathrm{hrs}\left(\mathrm{r}=-0.512, \mathrm{t}_{22}=2.79, \mathrm{p}<0.001\right)$; and 329 winter, $p l=-1 \mathrm{hr}\left(\mathrm{r}=-0.665, \mathrm{t}_{22}=4.18, \mathrm{p}<0.0005\right.$, Table 4).

330 


\section{Discussion}

333 This study describes the first investigation into the activity patterns of a range of mammal species

334 on the island of Ireland, adding to information gathered from across the species' ranges and to

335 those where little is recorded. The study also contributes to the growing body of literature that uses

336 remote camera traps to infer activity (e.g. Bridges \& Noss, 2011; Monterroso et al., 2013; Ross et

337 al., 2013; Carbajal-Borges et al., 2014; Allen et al., 2018) and reveals that our focal species exhibit

338 differences in activity relative to sunrise/sunset and throughout the year. In some cases, activity

339 changed markedly. For example, pine martens and rabbits were more diurnal in the summer while

340 during the rest of the year they were nocturnal and cathemeral, respectively. Similarly, predator-

341 prey relationships were also found to vary throughout the year. The temporal overlap between the

342 activity patterns of foxes, lagomorphs (rabbits and hares) and wood mice, were high ( $>0.75)$ during

343 the spring and summer and declined during autumn and winter. It is important to acknowledge

344 that a wide variety of factors affect activity patterns and, while our data show positive correlations

345 in activity between some predator and prey species that could be indicative of a causal relationship,

346 we do not attempt to describe observed patterns as being driven by any specific stimulus.

Foxes were nocturnal with their activity increasing during dusk and decreasing at dawn, although there was also some activity during daylight. The bimodal activity pattern suggested by previous studies (e.g. Reynolds \& Tapper, 1995) was not evident. Rural fox activity may be influenced by anthropogenic disturbance; diurnal activity is more common where disturbance is

351 low (e.g. Díaz-Ruiz et al., 2016; Gorman, 2008). In the present study, however, diurnal activity may have been facilitated, not by a lack of disturbance, but by the timing of the disturbance. Foxes are subject to nocturnal lethal control (i.e. shooting, facilitated by high-powered spot-lamps, and other methods) across Northern Ireland, such that nocturnal disturbance by hunting parties is likely 
355 to be considerably greater than that which occurs during the day, albeit periodically. However,

356 nocturnal control, while frequent, is regionally variable and intermittent. Furthermore, the most

357 abundant and commonly taken prey animals are nocturnal (e.g. small rodents) or crepuscular (e.g.

358 lagomorphs). Irregularities in the activity patterns described herein may therefore be indicative of

359 the true activity signal along with occasional temporal displacement. and 23:00, and 04:00 and 08:00. Diurnal activity was most commonly recorded in the summer months, when nights are shortest (sensu Flux \& Angermann, 1990, Holley, 1992, Langbein et al., 1999). This study is the first to quantify activity patterns of the Irish hare, which exhibited the same bimodal crepuscular-nocturnal behaviour as the European hare. The Irish hare is a subspecies of mountain hare that is endemic to Ireland while the European hare is almost exclusively found in Mid-Ulster, likely having been introduced in the 1970s (Caravaggi et al., 2015). Previous studies have demonstrated that the species are ecologically similar (Reid, 2011; Caravaggi et al., 2015), occur in sympatry (Caravaggi et al., 2016) and exhibit a high degree of bidirectional hybridisation (Prodohl et al., 2013). The similarity in activity patterns described herein adds additional support to the suggestion that strong interspecific competition is likely where they occur in sympatry where resources are limiting. The activity patterns of rabbits were similar to those in the Mediterranean region where rabbits were active throughout the day, but most activity occurred in the early morning and late afternoon (Monterroso et al., 2013). However, while our data suggest a similar bimodal pattern, the second, evening peak was weak in our dataset. and early autumn, similar to patterns reported elsewhere in the species' range (e.g. Monterroso et 377 al., 2013; Zalewski, 2007; Zielinksi et al., 1983). Previous studies have suggested that pine marten 
378 activity patterns may be linked to those of prey species (Zielinski et al., 1983). The relationship

379 between predator and prey is highlighted by the suggestion that pine martens may play a role in

380 the control of the invasive grey squirrel, to the benefit of the native red (Sheehy \& Lawton, 2014).

381 Although we have no direct evidence of this, pine marten activity in this study overlapped

382 considerably with that of the wood mouse in summer and winter. Studies indicate the importance

383 of wood mice to pine marten in Ireland in the absence of field voles (Lynch \& McCann, 2007;

384 O’Meara et al., 2013; Twining et al., 2018) and seasonal comparisons, in particular, show that

385 wood mice are a major food source in all seasons but autumn (Twining et al., 2018) which is

386 reflected in the correlation of activity reported here.

Squirrel activity peaked several hours after dawn and ceased before sunset. The species

were almost exclusively diurnal between seasons, with detections occurring throughout the day (Tonkin, 1983; Gurnell \& Hare, 2008). There was some evidence of variation of circadian patterns between seasons, with detections suggesting a bimodal pattern in the summer, and a unimodal pattern in the winter. The bimodularity observed in summer was caused by low activity around 392 midday, possibly in response to increased temperatures (Tonkin, 1983; Zub et al., 2013). Similar seasonal variation in activity has been observed in previous studies (e.g. Thompson, 1977; Tonkin, 1983; Gurnell \& Hare; 2008). Sunrise/set offsets revealed some crepuscular/diurnal activity, particularly during autumn and winter, behaviour that has not been reported in previous studies (e.g. Tonkin 1983; Wauters \& Dhondt 1987; Wauters et al., 1992). Foraging animals balance the risk of predation against the benefits of energy gains (Dammhahn \& Almeling, 2012) and the acuity of squirrel eyesight is sub-optimal in low-light conditions (i.e. dawn/dusk; Jacobs, Birch \& Blackeslee, 1982). Crepuscular activity may, therefore, be a response to local predator activity, thus rendering an apparently suboptimal strategy contextually advantageous (Dammhahn \& 
401 Almeling, 2012). The drivers of the observed crepuscular behaviour are unknown and are worthy

402 of further study.

403

Wood mice were nocturnal, although there was an increase in crepuscular and diurnal

404

405

406

407

408

409

410

411

412

413

414

415

416

417

418

419

420

421

422

423

activity recorded during summer when shorter nights may provide insufficient foraging time for lactating female wood mice to meet their daily energetic requirements. Juveniles recently out of the nest also may be active during daylight hours (Ian Montgomery, pers. obs.). The species has previously been reported to exhibit temporal variability in activity patterns between seasons (Miller \& Elton, 1955, Wolton, 1983). Wood mouse detections were chance occurrences as none of the camera trap projects that comprise this study specifically focussed on small mammals. However, while small mammals may present identification challenges to camera trap studies (e.g. Claridge et al., 2010; Meek \& Vernes, 2016), wood mice were attracted to arboreal baiting stations, often being the most recorded species. In contrast to other small mammals in Ireland, wood mice are known to be arboreal, so the methodology used could be applied elsewhere in the world to improve our knowledge of cryptic small mammals.

Anti-predator behaviours, which include avoidance (e.g. Curé et al., 2013), facilitate the survival of the prey by mitigating predation (Sih \& Christensen, 2001). In the current study, foxes consistently occurred in sympatry with hares and rabbits, both of which are putative prey species (Reynolds \& Aebischer, 1991). Both predator-prey annual cross-correlations indicated that foxes and lagomorphs are likely to be active simultaneously. In temperate zones, foxes typically mate in late winter/early spring; litters may contain up to 12 cubs, with food availability being a significant factor (Larivière \& Pasitschniak-Arts, 1996). Here we describe foxes as becoming increasingly crepuscular in late-spring and summer, thus increasing the potential for temporal overlap with both species of lagomorph. This suggests that predation of these species may increase during the fox 
424 breeding season. Indeed, lagomorphs may become an increasingly important food source as the 425 cubs grow, particularly if the vixen has many offspring, as both lagomorphs are amongst the most 426 substantial meals available to a medium-sized terrestrial predator in Northern Ireland. Given the 427 relative lack of carnivores in the country, we can be reasonably confident that the behavioural 428 repertoires of both hares and rabbits in Northern Ireland include fox-specific anti-predator 429 behaviours. Pine marten and squirrels showed a direct negative correlation in the annual 430 comparison, as well as during spring, summer, and winter. Thus, predator and prey activity are 431 simultaneously different (i.e. when pine martens are most active, squirrels are least active and viceversa). Squirrels are also subject to predation by diurnal birds of prey (e.g. Petty et al., 2003); by avoiding nocturnal predators, the animals become diurnally vulnerable. However, while squirrels

434 have relatively poor nocturnal vision (Arden \& Silver, 1962); their spatial acuity improves under 435 brighter conditions (Jacobs, Birch \& Blackeslee, 1982). Foraging during the night thus greatly 436 increases the risk of predation. individually-designed surveys. For example, there was considerable variation in the effective densities of camera trapping arrays. Higher density arrays increase the chances of capturing an animal in-transit, being placed near a resting site (i.e. sett, drey, form, etc.), and capturing the focal species if it occurs at low densities. Camera trap surveys, therefore, would ideally consistently use

442 high-density arrays to return an abundance of data. This is rarely feasible, however, given time, personnel, and financial constraints, all of which were limiting factors to the contributing surveys,

444 though, the involvement of trained citizen scientists spreads workload and increases the amount or 445 data available for analysis (e.g. Swanson et al., 2015). However, one of the key strengths of camera trap research is the ability to collate data from disparate, methodologically unique studies to 
447 describe fundamental ecological parameters. Moreover, the potential importance of bycatch data

448 from camera trap surveys cannot be over-stated and it is important that data can be aggregated

449 across independent surveys to answer relevant questions. space, thus decreasing the likelihood of a random capture in transit. Squirrels were enticed to specific locations for image capture by the use of baited stations. While baiting is certainly

453 effective, it is not without its problems. For example, animals may identify bait stations as a reliable source of food, and thus frequently revisit them, thereby inflating counts (Rowcliffe \& Carbone, 2008). Moreover, feeding animals may spend a considerable amount of time in front of the camera if undisturbed than those captured in transit, again affecting interpretations. The degree of uncertainty increases considerably where the focal species does not exhibit individuallyidentifiable colouration or markings. Captures from baited stations, therefore, may only represent one, or a handful of individuals (Trolle \& Kéry 2003, Weckel et al., 2006). However, the present study is only concerned with activity, and, hence, the detection of any individual during a given time period was assumed to be representative of the species as a whole. It should also be noted that the data used in the present study are uncorrected for detection probability. Thus, observed patterns could represent changes in animal activity, abundance or detectability over time. For example, ambient noise can affect individual behaviour (Francis \& Barber, 2013), subsequently impacting the number of detections recorded during camera trap surveys along with associated data and inferences. While we acknowledge that many factors will impact the detectability of a 467 species, including the height of emergent vegetation, camera placement, lighting condition (e.g. 468 daytime/night time), and the density and behaviour of the focal species (e.g. O'Brien et al. 2003; 
470 O’Connell et al., 2010; Chandler et al., 2011; Meek et al., 2014; Cusack et al., 2015; Meek et al.,

471 2016), we are confident that, given our sample sizes, the data presented herein reflect actual

472 activity patterns of the reported species.

474 considerable benefit in furthering our understanding of species ecologies and informing future research (e.g. the development and application of efficient ecological surveys), thus paving the way for the development of appropriate management policies and/or conservation programmes.

477 Knowing when a species is most or least likely to be active can lead to considerable methodological 478 improvements, including potentially reducing the probability of achieving false-negatives, 479 particularly for scarce or cryptic species. Camera trap surveys seeking to investigate circadian and intra-annual species activity patterns should, ideally, be conducted over the course of an entire year, focussing on areas which the focal species are known to frequent, and employing a large number of traps. Furthermore, additional data such as climate, topography and habitat may further inform interpretations and facilitate the application of statistical models. While the temporal 484 distribution of data herein are arguably suboptimal due to the application of varied (i.e. nonstandardised) methodologies, and environmental data are lacking, they are nevertheless of great utility in describing fundamental aspects of species' ecologies.

\section{Conclusions}

Camera traps allow practitioners to concurrently survey across a wide range of species and habitats, providing data that may be of great utility in informing subsequent investigations and/or answering important ecological questions. In the present study, we draw together several disparate, 
492 and very different camera trap surveys to describe fundamental behavioural parameters of ten

493 mammal species. We found that focal-species-specific and associated bycatch data derived from

494 camera traps are effective in providing insight into the daily lives of mammals. In particular, they

495 have provided an effective means of describing circadian activity patterns and seasonal variations

496 in temporal activity. In addition, they have utility in investigating temporal aspects of interspecific

497 interactions and directing further research into such relationships. Invasive alien species are an

498 ongoing issue and mitigating the threats posed to Irish hares and red squirrels by their respective

499 conspecifics and potential predators requires accurate ecological data to effectively guide

500 conservation efforts. Furthermore, prey switching is an issue with regards to carnivores of

501 conservation interest (e.g. pine martens) and shifts in the activity patterns of disease vectors (e.g.

502 deer, badgers) are relevant to their control. As many of the species described herein are of

503 economic, management and/or conservation interest, our data will help inform the development of

504 appropriate species-specific methodologies and processes and associated policies.

506 Acknowledgments

507 Thanks to the great many support staff, fieldworkers and landowners who were involved in the 508 surveys which contributed to this manuscript. We also thank three reviewers, whose feedback 509 helped guide improvements to the manuscript. 
510

511

512

513

514

515

516

517

518

519

520

521

522

523

524

525

526

527

528

529

530

531

532

533

534

535

536

537

538

539

540

541

542

\section{References}

Allen ML, Peterson B, Krofel M. 2018. No respect for apex carnivores: Distribution and activity patterns of honey badgers in the Serengeti. Mammalian Biology. 89:90-94.

Arden GB, Silver PH. 1962. Visual thresholds and spectral sensitivities of the grey squirrel (Sciurus carolinensis leucotis). The Journal of Physiology. 163:540-57.

Ashby KR. 1972. Patterns of daily activity in mammals. Mammal Review 1:171-185.

Baker PJ, Harris S. 2006. Does culling reduce fox (Vulpes vulpes) density in commercial forests in Wales, UK? European Journal of Wildlife Research. 52:99-108.

Bennie JJ, Duffy JP, Inger R, Gaston KJ. 2014. Biogeography of time partitioning in mammals. Proceedings of the National Academy of Sciences. 111:13727-13732.

Bradley WG. 1967. Home range, activity patterns, and ecology of the antelope ground squirrel in southern Nevada. The Southwestern Naturalist. 12: 231-251.

Bridges AS, Noss AJ. 2011. Behaviour and activity patterns. In: O'Connell AF, Nichols JD, Karanth eds) Camera traps in animal ecology: Methods and analyses. 57-69. Springer, New York.

Cagnacci F, Boitani L, Powell RA, Boyce MS. 2010. Animal ecology meets GPS-based radiotelemetry: a perfect storm of opportunities and challenges. Philosophical Transactions of the Royal Society B: Biological Sciences. 365: 2157-2162.

Caravaggi A, Gatta M, Vallely M-C, Hogg K, Freeman M, Fadei E, Dick J, Montgomery WI, Reid N, Tosh D. 2018. arcaravaggi/PeerJ_mammal_activity: Code \& data archive (Version v1.0.0). Zenodo. http://doi.org/10.5281/zenodo.1420397

Caravaggi A, Montgomery WI, Reid N. 2015. Range expansion and comparative habitat use of insular, congeneric lagomorphs: invasive European hares Lepus europaeus and endemic Irish hares Lepus timidus hibernicus. Biological Invasions. 17: 687-698.

Caravaggi A, Zaccaroni M, Riga F, Schai-Braun SC, Dick JT, Montgomery WI, Reid N. 2016. An invasive-native mammalian species replacement process captured by camera trap survey random encounter models. Remote Sensing in Ecology and Conservation. 2:45-58.

Carbajal-Borges JP, Godínez-Gómez O, Mendoza E. 2014. Density, abundance and activity patterns of the endangered Tapirus bairdii in one of its last strongholds in southern Mexico. Tropical Conservation Science. 7:100-114.

Carden RF, Carlin CM, Marnell F, McElholm D, Hetherington J, Gammell MP. 2011. Distribution and range expansion of deer in Ireland. Mammal Review. 41:313-325.

Caryl FM, Raynor R, Quine CP, Park K. (2012). The seasonal diet of British pine marten determined from genetically identified scats. Journal of Zoology, 288, 252 - 259. 
543 Chandler RB, Royle JA, King DI. 2011. Inference about density and temporary emigration in 544 unmarked populations. Ecology. 92:1429-1435.

545 Claridge AW, Paull DJ, Barry SC. 2010. Detection of medium-sized ground-dwelling mammals 546 using infrared digital cameras: an alternative way forward? Australian Mammalogy. 32:165-71.

547 Curé C, Antunes R, Alves AC, Visser F, Kvadsheim PH, Miller PJO. 2013. Responses of male 548 sperm whales (Physeter macrocephalus) to killer whale sounds: implications for anti-predator 549 strategies. Scientific Reports. 3:1579.

550 Cusack JJ, Dickman AJ, Rowcliffe JM, Carbone C, Macdonald DW, Coulson T., 2015. Random 551 versus game trail-based camera trap placement strategy for monitoring terrestrial mammal 552 communities. PloS One. 10:p.e0126373.

553 Daan S. 1981. Adaptive daily strategies in behavior. In: Aschoff J, ed. Biological Rhythms, 275554 298. Springer, Boston, MA.

555 Dammhahn M, Almeling L. 2012. Is risk taking during foraging a personality trait? A field test for 556 cross-context consistency in boldness. Animal Behaviour. 84: 1131-1139.

557 Department of Agriculture, Environment and Rural Affairs (2018) Statistical Review of Northern 558 Ireland Agriculture 2017. DAERA.

559 Di Cerbo AR, Biancardi CM. 2013. Monitoring small and arboreal mammals by camera traps: effectiveness and applications. Acta Theriologica. 58:279-283.

561 Díaz-Ruiz F, Caro J, Delibes-Mateos M, Arroyo B, Ferreras P. 2016. Drivers of red fox (Vulpes

562 vulpes) daily activity: prey availability, human disturbance or habitat structure?. Journal of 563 Zoology. 298: 128-138.

564 EEA. 2010. Corine Land Cover 2006 raster data. Available at: https://land.copernicus.eu/pan565 european/corine-land-cover/clc-2012. (Accessed 13 March 2016).

566 Elton C, Ford EB, Baker JR, Gardner AD. 1931. The health and parasites of a wild wood mouse 567 population. Proceedings of the Zoological Society, London. 101: 657-721.

568 Ensing EP, Ciuti S, de Wijs FA, Lentferink DH, ten Hoedt A, Boyce MS, Hut RA. 2014. GPS 569 based daily activity patterns in European red deer and North American elk (Cervus elaphus): 570 indication for a weak circadian clock in ungulates. PLoS One. 9: e106997.

571 Fairley JS. 1970. The food, reproduction, form, growth and development of the fox Vulpes vulpes 572 (L.) in North-East Ireland. Proceedings of the Royal Irish Academy. 69:103-137.

573 Fenn MG, Macdonald DW. 1995. Use of middens by red foxes: risk reverses rhythms of rats. 574 Journal of Mammalogy. 76:130-136. 
575 Flux JEC, Angermann R. 1990. The hares and jackrabbits. In: Chapman JA, Flux JEC, eds. 576 Rabbits, hares and pikas: status survey and conservation action plan, 76-78. IUCN/SSC 577 Lagomorph Specialist Group, Oxford.

578 Forestry Comission (2018) Woodland Area, Planting and Publicly Funded Restocking. 2018 579 Edition First Release.

580 Francis CD, Barber JR. 2013. A framework for understanding noise impacts on wildlife: an urgent conservation priority. Frontiers in Ecology and the Environment. 11:305-313.

582 Griffin JM, Williams DH, Kelly GE, Clegg TA, O’Boyle I, Collins JD, More SJ. 2005. The impact 583 of badger removal on the control of tuberculosis in cattle herds in Ireland. Preventive Veterinary 584 Medicine. 67:237-266.

585 Gurnell J, Hare EJ. 2008. Rodents. In: Harris S, Yalden DW, eds. Mammals of the British Isles, 586 54-199. The Mammal Society, Southampton.

587 Halle S, Stenseth NC. 2000. Introduction. In: Halle S, Stenseth NC, eds. Activity patterns in small 588 mammals - an ecological approach, 3-17. Springer, Berlin.

589

590

591

592

593

594

595

596

597

598

599

600

601

602

603 604

605

606

607

608

Harmsen BJ, Foster RJ, Silver S, Ostro L, Doncaster CP. 2010. Differential use of trails by forest mammals and the implications for camera-trap studies: a case study from Belize. Biotropica. 42:126-133.

Hertel AG, Zedrosser A, Mysterud A, Støen OG, Steyaert SM, Swenson JE. 2016. Temporal effects of hunting on foraging behavior of an apex predator: Do bears forego foraging when risk is high?. Oecologia. 182: 1019-1029.

Hetem RS, Strauss WM, Fick LG, Maloney SK, Meyer LCR, Shobrak M, Fuller A, Mitchell D. 2012. Does size matter? Comparison of body temperature and activity of free-living Arabian oryx (Oryx leucoryx) and the smaller Arabian sand gazelle (Gazella subgutturosa marica) in the Saudi desert. Journal of Comparative Physiology B. 182:437-449.

HM Nautical Almanac Office. 2016. HM nautical almanac office: on-line data. Available at http://astro.ukho.gov.uk/nao/online/. (Accessed $17^{\text {th }}$ February 2016).

Hofmeester TR, Rowcliffe JM, Jansen PA. 2017. A simple method for estimating the effective detection distance of camera traps. Remote Sensing in Ecology and Conservation. 3:81-89.

Holley AJF. 1992. Studies on the biology of the brown hare (Lepus europaeus) with particular reference to behaviour. $\mathrm{PhD}$ thesis. Durham University.

Hoogenboom I, Daan S, Dallinga JH, Schoenmakers M. 1984. Seasonal change in the daily timing of behaviour of the common vole, Microtus arvalis. Oecologia. 61:18-31.

Jacobs GH, Birch DG, Blakeslee B. 1982. Visual acuity and spatial contrast sensitivity in tree squirrels. Behavioural Processes. 7:367-75. 
609 Jones KR, Bielby J, Cardillo M, Fritz SA, O'Dell J, Orme CDL, Safi K, Sechrest W, Boakes E, 610 Carbone C, Connolly C, Cutts MJ, Foster JK, Grenyer R, Habib M, Plaster CA, Price SA, Rigby

611 EA, Rist R, Teacher A, Bininda-Emonds ORP, Gittleman JL, Mace GM, Purvis A. 2009.

612 PanTHERIA: a species-level database of life history, ecology, and geography of extant and

613 recently extinct mammals. Ecology. 90:2648.

614 Karanth KU, Nichols JD, Kumar NS, Hines JE. 2006. Assessing tiger population dynamics using 615 photographic capture-recapture sampling. Ecology. 87:2925-2937.

616 Kays RW, Slauson KM. 2008. Remote cameras. In: Long RA, MacKay P, Zielinski WJ, Ray JC, 617 eds. Noninvasive survey methods for carnivores, Island Press, Washington DC.

618 Kronfeld-Schor N, Dayan T. 2003. Partitioning of time as an ecological resource. Annual 619 Review of Ecology, Evolution, and Systematics. 34:153-181.

620 Kucera TE, Barrett R. 2011. A history of camera trapping. In: O'Connell AF, Nichols JD, Karanth 621 KU, eds. Camera traps in animal ecology: methods and analysis, 9-26. Springer, New York.

622 Langbein J, Hutchings MR, Harris S, Stoate C, Tapper SC, Wray S. 1999. Techniques for assessing 623 the abundance of brown hares Lepus europaeus. Mammal Review. 29:93-116.

624 Larivière S, Huot J, Samson C. 1994. Daily activity patterns of female black bears in a northern 625 mixed-forest environment. Journal of Mammalogy. 75: 613-620.

626 Larivière S, Pasitschniak-Arts M. 1996. Vulpes vulpes. Mammalian Species: 1-11.

627 Larrucea ES, Brussard PF, Jaeger MM, Barrett RH. 2007. Cameras, coyotes, and the assumption 628 of equal detectability. The Journal of Wildlife Management. 71:1682-1689.

629 Leso P, Kropil R. 2010. Influence of some methodological modifications on trapping efficiency 630 and mortality of small terrestrial mammals (Rodentia). Lynx. 41:167-173.

631 Linkie M, Dinata Y, Nugroho A, Haidir IA. 2007. Estimating occupancy of a data deficient 632 mammalian species living in tropical rainforests: Sun bears in the Kerinci Seblat region, Sumatra. 633 Biological Conservation. 137:20-27.

634 Lode T. 1995. Activity pattern of polecats Mustela putorius L. in relation to food habits and prey 635 activity. Ethology. 100:295-308.

636 Lovari S, Valier P, Lucchi MR. 1994. Ranging behaviour and activity of red foxes (Vulpes vulpes: 637 Mammalia) in relation to environmental variables, in a Mediterranean mixed pinewood. Journal 638 of Zoology. 232:323-339.

639 Lynch AB, McCann Y. 2007. The diet of the pine marten (Martes martes) in Killarney National 640 Park. Biology and Environment: Proceedings of the Royal Society of Ireland. 107B:67-76. 
641 Maffei L, Noss AJ, Cuéllar E, Rumiz DI. 2005. Ocelot (Felis pardalis) population densities, 642 activity, and ranging behaviour in the dry forests of eastern Bolivia: data from camera trapping. 643 Journal of Tropical Ecology. 21:349-353.

644 Meredith M, Ridout M. 2017. overlap: Estimates of Coefficient of Overlapping for Animal 645 Activity Patterns. R package version 0.3.0. Available at: https://CRAN.R-

646 project.org/package=overlap (Accessed 07 January 2018).

647 Merrill SB, Mech LD. 2003. The usefulness of GPS telemetry to study wolf circadian and social 648 activity. Wildlife Society Bulletin. 947-960.

649 Meek PD, Ballard GA, Falzon G. 2016. The higher you go the less you will know: placing camera 650 traps high to avoid theft will affect detection. Remote Sensing in Ecology and Conservation. 2:204651211.

652 Meek PD, Ballard G, Claridge A, Kays R, Moseby K, O’Brien T, O’Connell A, Sanderson J, 653 Swann DE, Tobler M, Townsend S. 2014. Recommended guiding principles for reporting on 654 camera trapping research. Biodiversity and Conservation., 23:2321-2343.

655 Meek PD, Vernes K, Falzon G. 2013. On the reliability of expert identification of small-medium 656 sized mammals from camera trap photos. Wildlife Biology in Practice. 9:1-19.

657 Meek PD, Vernes K. 2016. Can camera trapping be used to accurately survey and monitor the 658 Hastings River mouse (Pseudomys oralis)? Australian Mammalogy 38:44-51.

659 Middleton AD, Kauffman MJ, McWhirter DE, Jimenez MD, Cook RC, Cook JG, Albeke SE, 660 Sawyer H, White PJ. 2013. Linking anti-predator behaviour to prey demography reveals limited 661 risk effects of an actively hunting large carnivore. Ecology Letters. 16:1023-1030.

662 Miller RS, Elton C. 1955. Activity rhythms in the Wood Mouse, Apodemus sylvaticus and the 663 Bank Vole, Clethrionomys glareolus. Proceedings of the zoological Society of London. 125:505664519.

665 Monterroso P, Alves PC, Ferreras P. 2013. Catch me if you can: diel activity patterns of 666 mammalian prey and predators. Ethology. 119:1044-1056.

667 Monterroso P, Alves PC, Ferreras P. 2014. Plasticity in circadian activity patterns of 668 mesocarnivores in Southwestern Europe: implications for species coexistence. Behavioral 669 ecology and sociobiology. 68:1403-1417.

670 Montgomery WI, Provan J, McCabe AM, Yalden SW. 2014. Origin of British and Irish 671 mammals: disparate post-glacial colonisation and species introductions. Quaternary Science 672 Reviews. 98:144-165.

673 Nouvellet P, Rasmussen GSA, Macdonald DW, Courchamp F. 2012. Noisy clocks and silent 674 sunrises: measurement methods of daily activity pattern. Journal of Zoology. 286:179-184. 
675 O'Connell AF, Nichols JD, Karanth KU. eds., 2010. Camera Traps in Animal Ecology: Methods

676 and Analyses. Springer Science \& Business Media.

677 O’Meara D, Sheehy E, Turner PD, O’Mahony D, Harrington AP, Denman H, Lawton C,

678 MacPherson J, O’Reilly C. 2013. Non-invasive multi-species monitoring: real-time PCR

679 detection of small mammal and squirrel prey DNA in pine marten (Martes martes) scats. Acta

680 Theriologica. 59:111-117.

681 Oliveira-Santos LGR, Zucco CA, Antunes PC, Crawshaw Jr PG. 2010. Is it possible to individually 682 identify mammals with no natural markings using camera-traps? A controlled case-study with 683 lowland tapirs. Mammalian Biology Zeitschrift fur Saugetierkunde. 75:375-378.

684 Palomares P, Delibes M. 1991. Assessing three methods to estimate daily activity patterns in radio685 tracked mongooses. Journal of Wildlife Management. 55:698-700.

686 Pereira JA. 2010. Activity pattern of Geoffroy's cats (Leopardus geoffroyi) during a period of 687 food shortage. Journal of Arid Environments. 74:1106-1109.

688 Petty SJ, Lurz PW, Rushton DIK. 2003. Predation of red squirrels by northern goshawks in a 689 conifer forest in northern England: can this limit squirrel numbers and create a conservation 690 dilemma? Biological Conservation. 111:105-114.

691 Phillips AJK, Fulcher BD, Robinson PA, Klerman EB. 2013. Mammalian rest/activity patterns 692 explained by physiologically based modeling. PLoS Computational Biology. 9:e1003213.

693 Prodohl PA, Hughes MA, Hynes RA, Montgomery WI, Reid N. 2013. Molecular evidence for 694 bidirectional hybridisation between the endemic Lepus timidus hibernicus and the invasive Lepus 695 europaeus in Ireland. In: Montgomery WI, ed. Proceedings of the 11th international 696 mammalogical congress, 77. Queen's University Belfast, Belfast.

697 Prugh LR, Golden CD. 2014. Does moonlight increase predation risk? Meta-analysis reveals 698 divergent responses of nocturnal mammals to lunar cycles. Journal of Animal Ecology. 83:504699514.

700 R Core Team. 2017.. R: A language and environment for statistical computing. R Foundation for 701 Statistical Computing, Vienna, Austria. Available at: https://www.R-project.org/ (Accessed 07 702 February 2018).

703 Reid N. 2011. European hare (Lepus europaeus) invasion ecology: implication for the 704 conservation of the endemic Irish hare (Lepus timidus hibernicus). Biological Invasions. 13:559705569.

706 Reid N, Montgomery WI. 2007. Is naturalisation of the brown hare in Ireland a threat to the 707 endemic Irish hare? Biology and Environment: Proceedings of the Royal Irish Academy. 708 107B:129-138. 
709 Reynolds JC, Aebischer NJ. 1991. Comparison and quantification of carnivore diet by faecal 710 analysis: a critique, with recommendations, based on a study of the fox Vulpes vulpes. Mammal 711 Review. 21:97-122.

712 Reynolds JC, Tapper SC. 1995. Predation by foxes Vulpes vulpes on brown hares Lepus 713 europaeus in central southern England, and its potential impact on annual population growth. 714 Wildlife Biology. 1:145-57.

715 Roll U, Dayan T, Kronfeld-Schor N. 2006. On the role of phylogeny in determining activity 716 patterns of rodents. Evolutionary Ecology. 20:479-490.

717 Ross J, Hearn AJ, Johnson PJ, Macdonald DW. 2013. Activity patterns and temporal avoidance

718 by prey in response to Sunda clouded leopard predation risk. Journal of Zoology. 290:96-106.

719 Rowcliffe JM, Carbone C. 2008. Surveys using camera traps: are we looking to a brighter future? 720 Animal Conservation 11:185-186.

721 Royle J, Nichols J. 2003. Estimating abundance from repeated presence-absence data or point 722 counts. Ecology. 84:777-790.

723 Rychlik L.2005. Overlap of temporal niches among four sympatric species of shrews. Acta 724 Theriologica. 50:175-188.

725 Sadlier LM, Webbon CC, Baker PJ, Harris S. 2004. Methods of monitoring red foxes Vulpes 726 vulpes and badgers Meles meles: are field signs the answer? Mammal Review. 34:75-98.

727 Schai-Braun SC, Rödel HG, Hackländer K. 2012. The influence of daylight regime on diurnal 728 locomotor activity patterns of the European hare (Lepus europaeus) during summer. Mammalian 729 Biology. 77:434-440.

730 Sheehy E, Lawton C. 2014. Population crash in an invasive species following the recovery of a 731 native predator: the case of the American grey squirrel and the European pine marten in Ireland. 732 Biodiversity Conservation. 23:753-774.

733 Sih A, Christensen B. 2001. Optimal diet theory: when does it work, and when and why does it 734 fail? Animal Behaviour. 61:379-390.

735 Silveira L, Jácomo ATA, Diniz-Filho JAF. 2003. Camera trap, line transect census and track 736 surveys: a comparative evaluation. Biological Conservation. 114:351-355.

737 Stewart PD, Ellwood SA, Macdonald DW. 1997. Remote video-surveillance of wildlife-an 738 introduction from experience with the European badger Meles meles. Mammal Review. 27:185739204.

740 Swann DE, Hass CC, Dalton DC, Wolf SA. 2004. Infrared-triggered cameras for detecting 741 wildlife: an evaluation and review. Wildlife Society Bulletin. 32:357-365. 
742 Swanson A, Kosmala M, Lintott C, Simpson R, Smith A, Packer C. 2015. Snapshot Serengeti, 743 high-frequency annotated camera trap images of 40 mammalian species in an African savanna. 744 Scientific Data. 2:p.150026.

745 Theuerkauf J, Jędrzejewski W, Schmidt K, Okarma H, Ruczyński I, Śnieżko S, Gula R. 2003.

746 Daily patterns and duration of wolf activity in the Białowieża Forest, Poland. Journal of

747 Mammalogy, 84:243-253.

748 Thompson DC. 1977. Diurnal and seasonal activity of the grey squirrel (Sciurus carolinensis).

749 Canadian Journal of Zoology. 55:1185-1189.

750 Thompson PM, Fedak MA, McConnell BJ, Nicholas KS. 1989. Seasonal and sex-related 751 variation in the activity patterns of common seals (Phoca vitulina). Journal of Applied Ecology. 752 26:521-535.

753 Tobler MW, Carrillo-Percastegui SE, Leite Pitman R, Mares R, Powell G. 2008a. An evaluation 754 of camera traps for inventorying large- and medium-sized terrestrial rainforest mammals. Animal 755 Conservation. 11:169-178.

756 Tobler MW, Carrillo-Percastegui SE, Leite Pitman R, Mares R, Powell G. 2008b. Further notes 757 on the analysis of mammal inventory data collected with camera traps. Animal Conservation. $758 \quad 11: 187-189$.

759

760

761

762

763

764

765

766

767

768

769

770

771

772

773

Tonkin JM. 1983. Activity patterns of the Red squirrel (Sciurus vulgaris). Mammal Review. 13:99_111.

Torre I, Guixe D, Sort F. 2010. Comparing three live trapping methods for small mammal sampling in cultivated areas of NE Spain. Italian Journal of Mammology. 21:147-155.

Trolle M, Kéry M. 2003. Estimation of ocelot density in the Pantanal using capture-recapture analysis of camera-trapping data. Journal of mammalogy. 84:607-614.

Twining JP, Tosh DG, Montgomery WI, Marks N, Scantlebury DM. 2018. Seasonal and habitat effects on diet of a recovering native predator in Ireland: the European pine marten (Martes martes). Manuscript in preparation.

van Doormaal N, Ohashi H, Koike S, Kaji K. 2015. Influence of human activities on the activity patterns of Japanese sika deer (Cervus nippon) and wild boar (Sus scrofa) in Central Japan. European journal of wildlife research. 61:517-527.

Wang Y, Allen ML, Wilmers CC. 2015. Mesopredator spatial and temporal responses to large predators and human development in the Santa Cruz Mountains of California. Biological Conservation. 190:23-33. 
774 Wauters LA., Dhondt AA. 1987. Activity budget and foraging behaviour of the red squirrel

775 (Sciurus vulgaris, Linnaeus, 1758) in a coniferous habitat. Zeitschrift für Säugetierkunde, 776 52:341-353.

777 Wauters L, Swinnen C, \& Dhondt AA. 1992. Activity budget and foraging behaviour of red

778 squirrels (Sciurus vulgaris) in coniferous and deciduous habitats. Journal of Zoology. 227:71-86.

779 Webbon CC, Baker PJ, Cole NC, Harris S. 2006. Macroscopic prey remains in the winter diet of 780 foxes Vulpes vulpes in rural Britain. Mammal Review. 36:85-97.

781 Weckel M, Giuliano W, Silver S. 2006. Jaguar (Panthera onca) feeding ecology: distribution of 782 predator and prey through time and space. Journal of Zoology. 270:25-30.

783 Wilson CD, Arnott G, Reid N, Roberts D. 2011. The pitfall with PIT tags: marking freshwater 784 bivalves for translocation induces short-term behavioural costs. Animal Behaviour. 81:341-346.

785 Wolton RJ. 1983. The activity of free-ranging wood mice Apodemus sylvaticus. The Journal of 786 Animal Ecology. 52: 781-794.

787 Zalewski A. 2007. Does size dimorphism reduce competition between sexes? The diet of male and 788 female pine martens at local and wider geographical scales. Acta Theriologica. 52:237-50.

789 Zielinski WJ, Spencer WD, Barrett RH. 1983. Relationship between food habits and activity 790 patterns of pine martens. Journal of Mammalogy. 64:387-96.

791 Zub K, Fletcher QE, Szafrańska PA, Konarzewski M. 2013. Male weasels decrease activity and 792 energy expenditure in response to high ambient temperatures. PloS ONE. 8:e72646. 
Figure 1

Locations of sites used in camera trap wildlife studies in Northern Ireland from 2013 2016.

For species-specific maps, see Fig. S3.

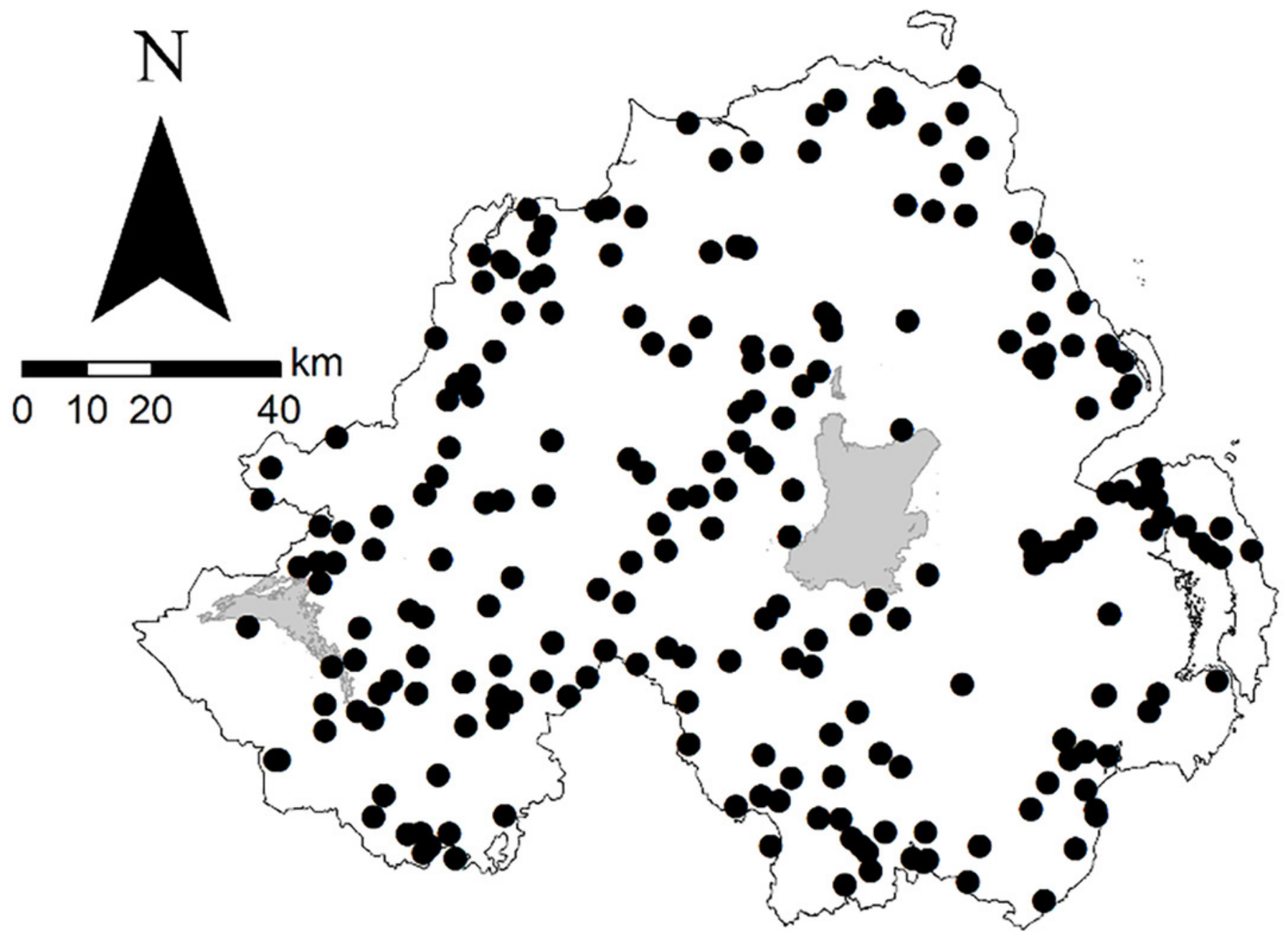


Figure 2

Camera trap images of ten mammal species detected in Northern Ireland between 2013-2016

(a) Badger, (b) fallow deer, (c) fox, (d) European hare, (e) Irish hare, (f) pine marten, (g) rabbit, (h) grey squirrel, (i) red squirrel, and (j) wood mouse (circled). Images provided by A. Caravaggi (a, e, h, j), K. Hogg and M. Freeman (b, $\mathbf{c}, \mathbf{g})$ and D.G. Tosh (f, i). 

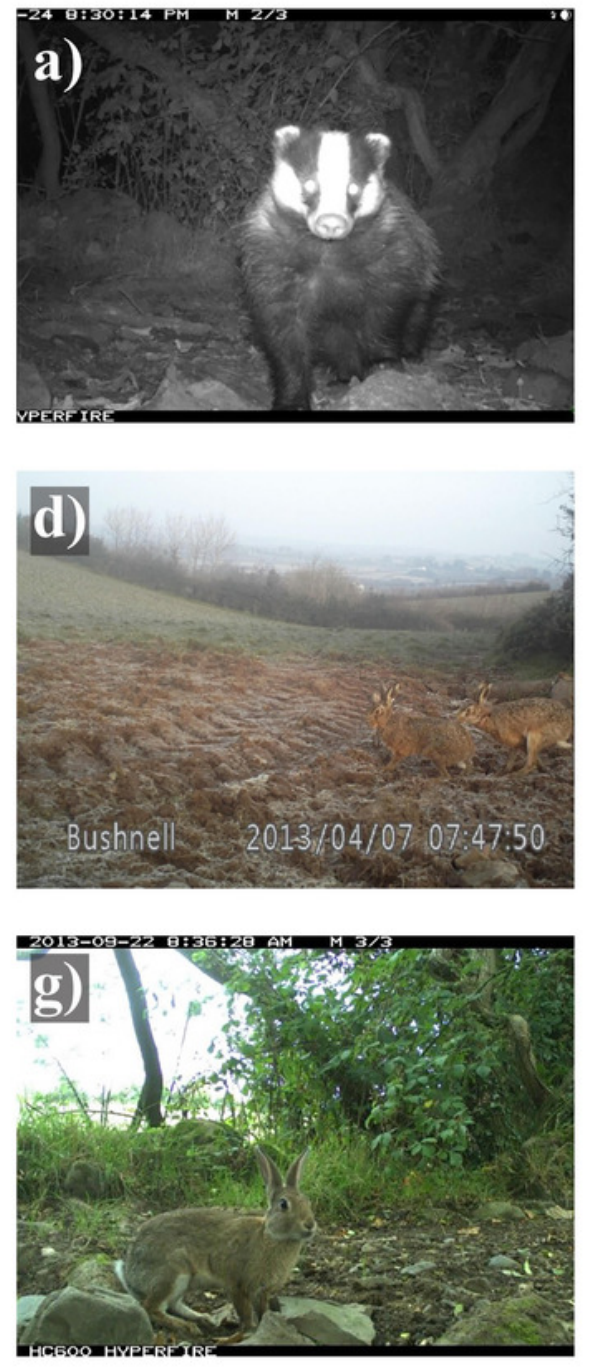
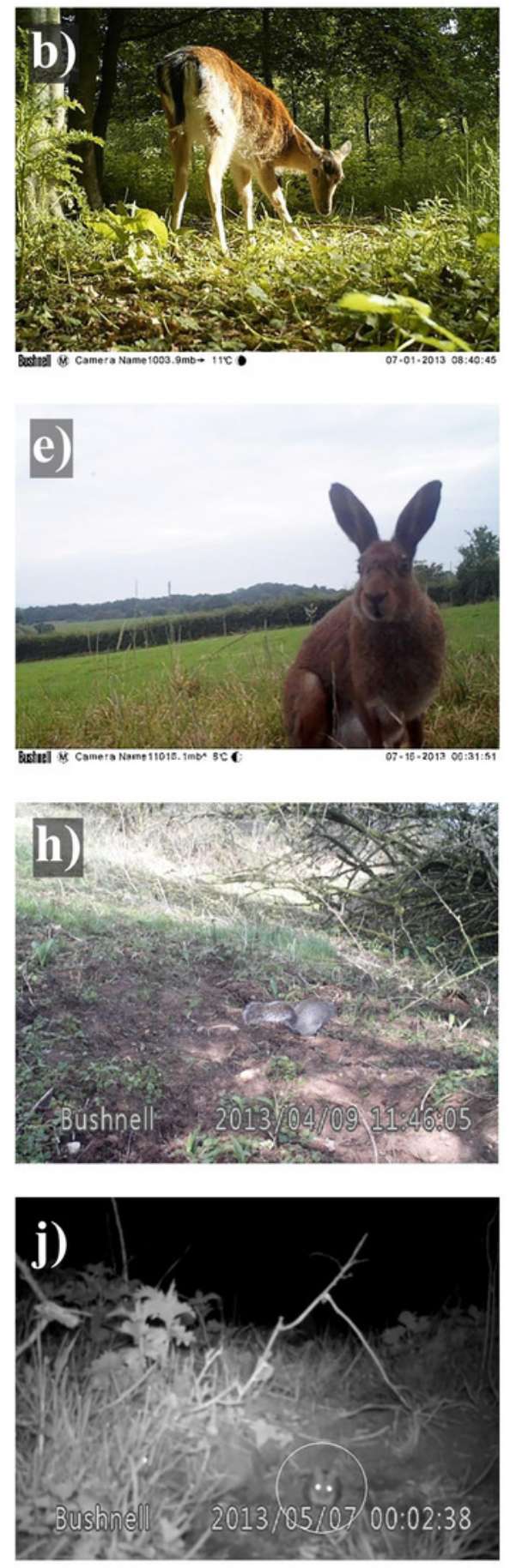
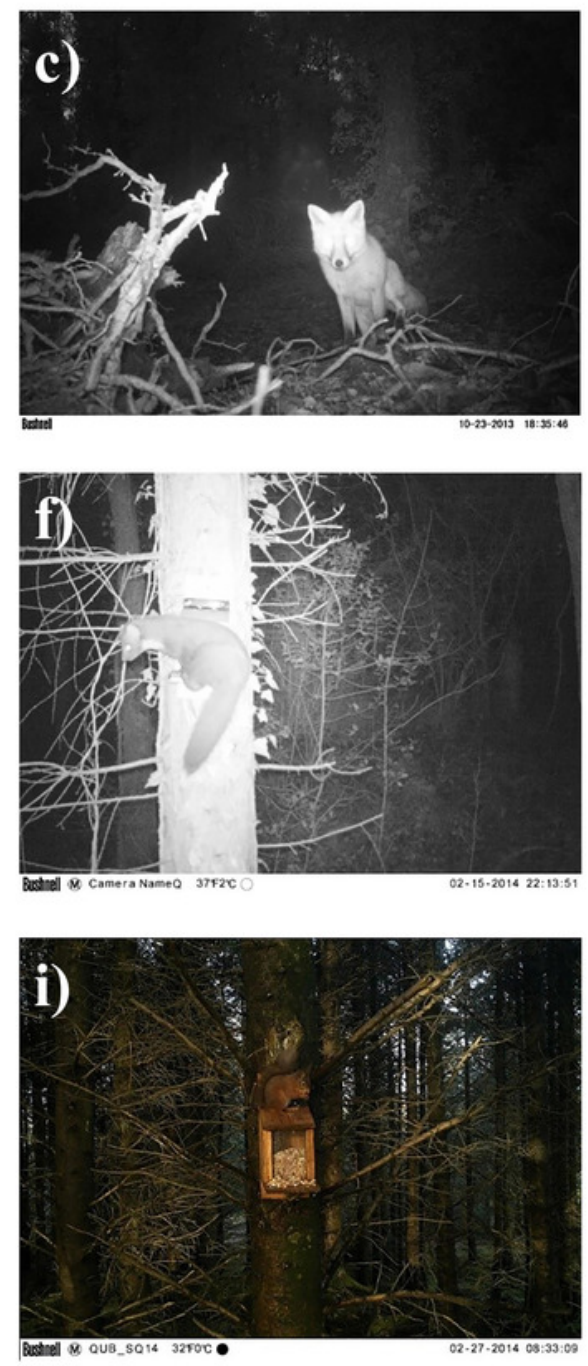


\section{Figure 3}

Circadian activity patterns of ten mammal species detected during camera trap surveys in Northern Ireland from 2013 - 2016.

(a) Fox (Vulpes vulpes) hare (Irish hare, Lepus timidus hibernicus, and European hare, L. europaeus; see Fig. S1) and rabbit (Oryctolagus cuniculus); (b) pine marten (Martes martes), wood mouse (Apodemus sylvaticus) and and squirrel (grey squirrel, Sciurus californicus, and red squirrel, Sciurus vulgaris; see Fig. S2); (c) badger (Meles meles) and fallow deer (Dama dama). Shaded areas represent night time. 


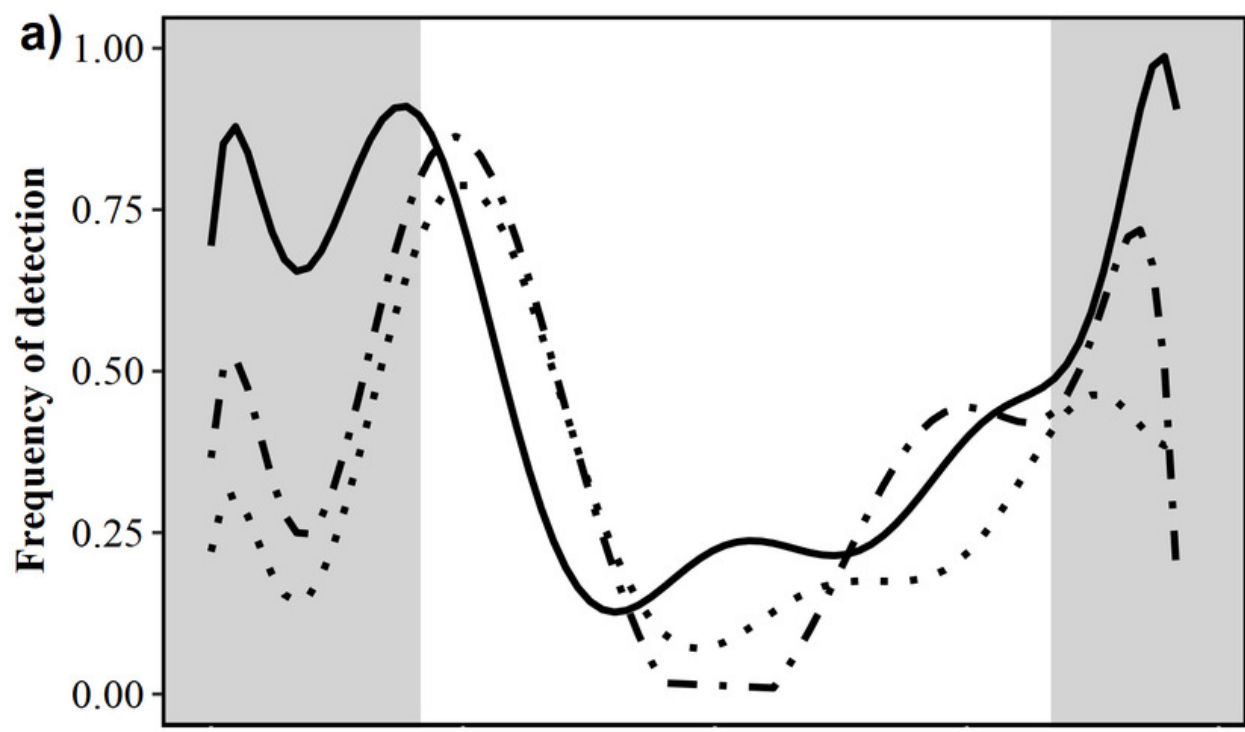

Species

- Fox

- Hare

- - Rabbit

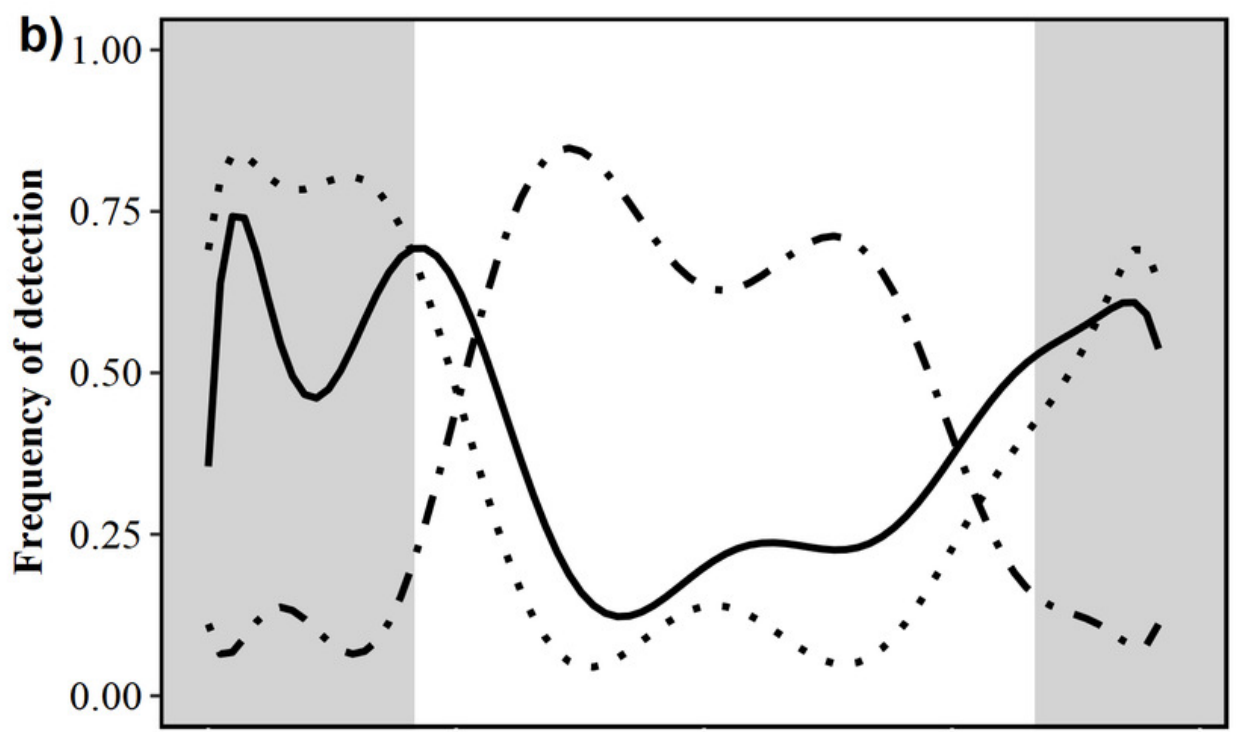

Species

— Pine marten

- Wood mouse

- - Squirrel

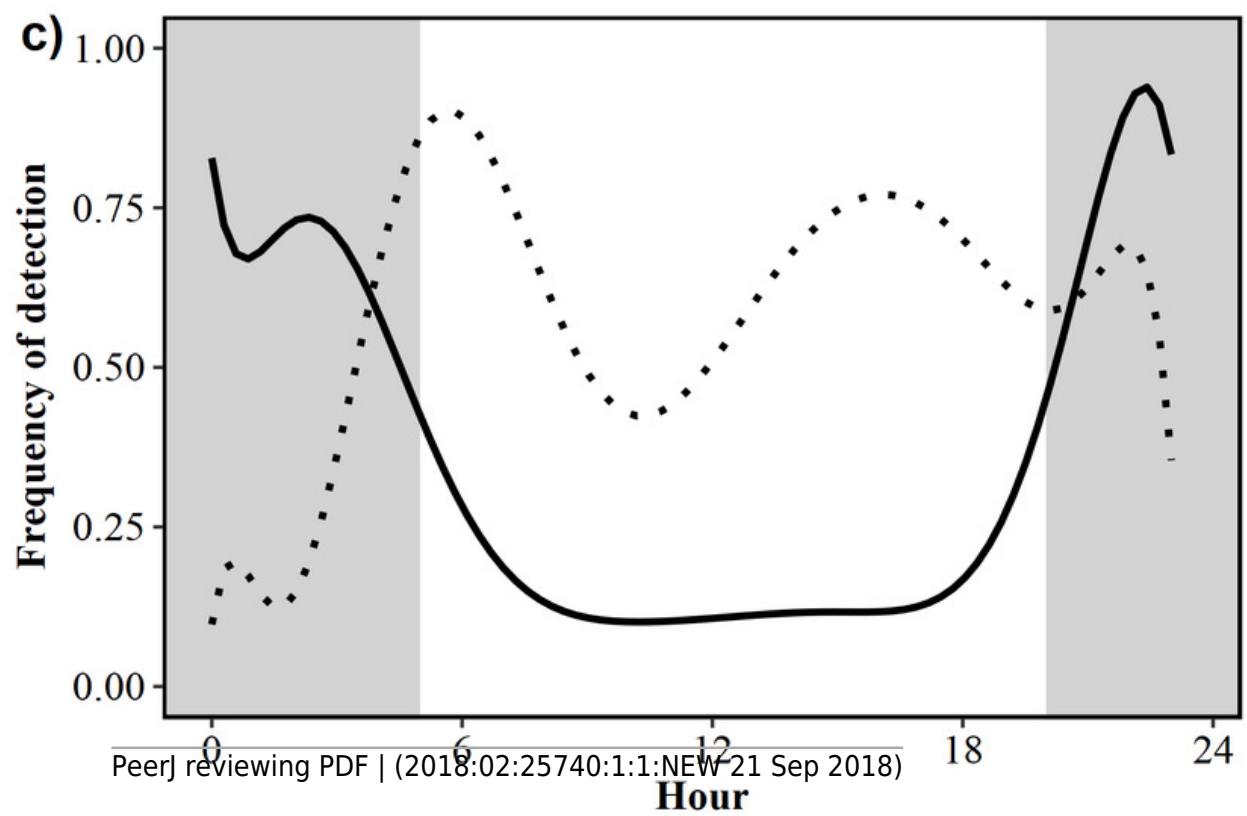

Species

- Badger

- Fallow deer 


\section{Figure 4}

Time of detection relative to sunrise/sunset during spring, summer, autumn, and winter for ten mammal species observed during camera trap surveys in Northern Ireland between $2013-2016$

(a) Badger, (b) fallow deer, (c) fox, (d) hare (Irish hare and European hare), (e) pine marten, (f) rabbit, (g) squirrel (grey squirrel and red squirrel), and (h) wood mouse. The upper, unshaded area denotes daytime, the lower, shaded area denotes night. Dashed lines indicate mean annual offset. Boxes represent the mean \pm Standard Deviation. Violin plots represent the density and spread of all contributing data points. 
a)

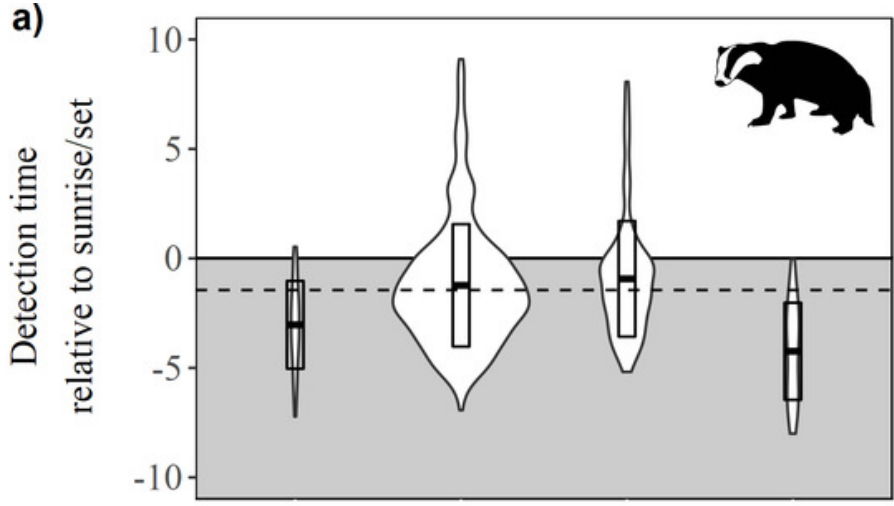

c)

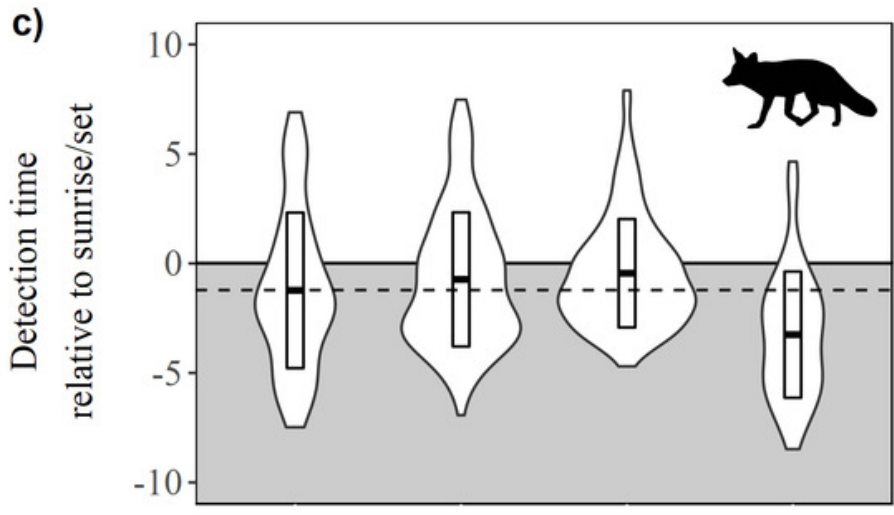

e)
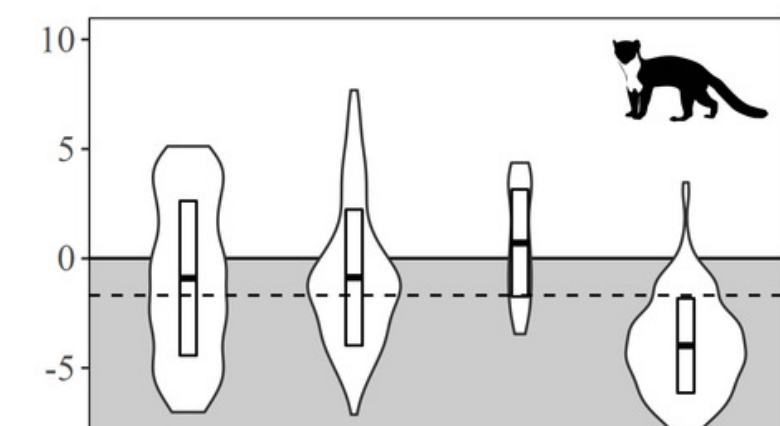

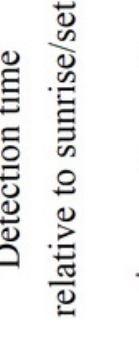

$-10$

g)

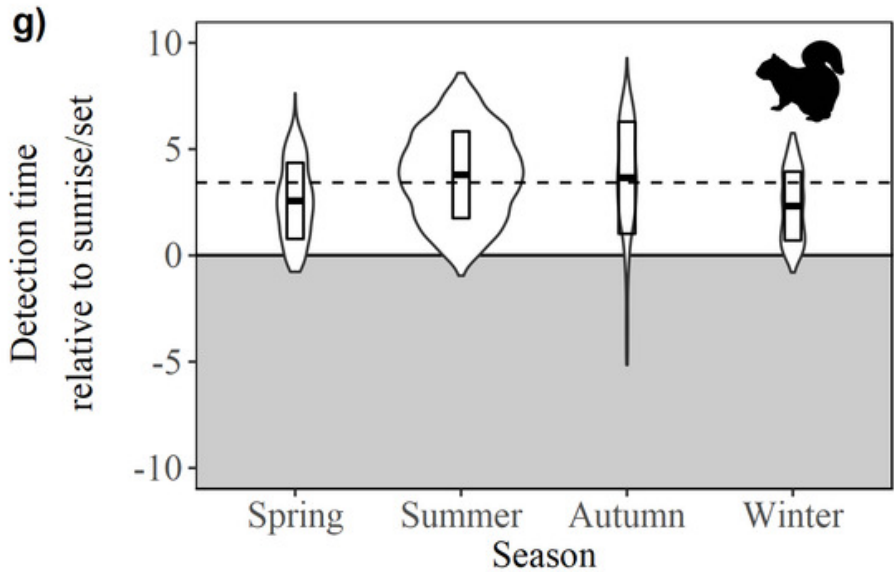

b)

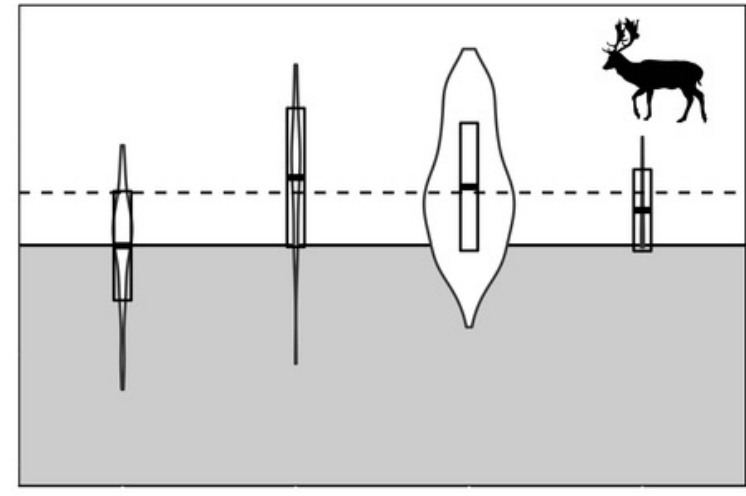

d)

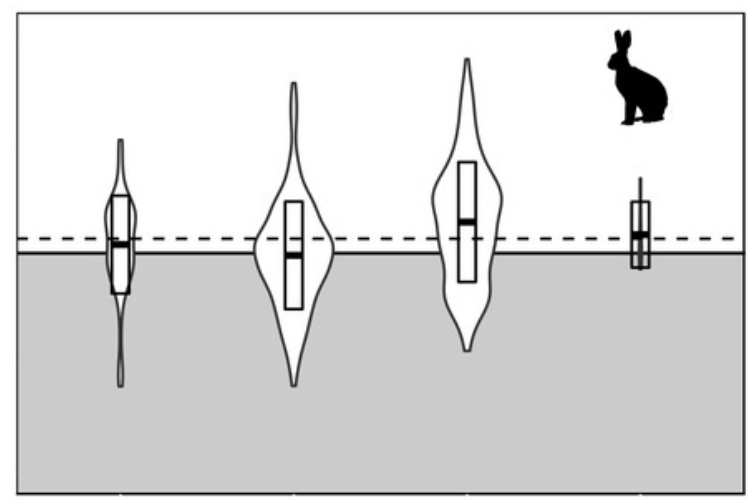

f)

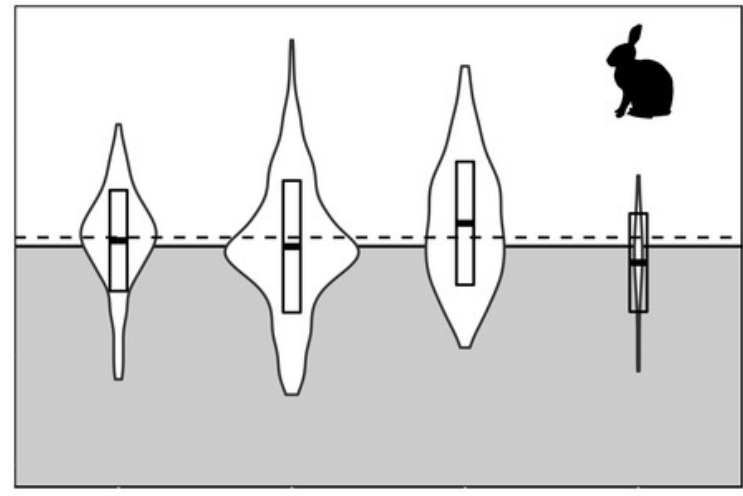

h)

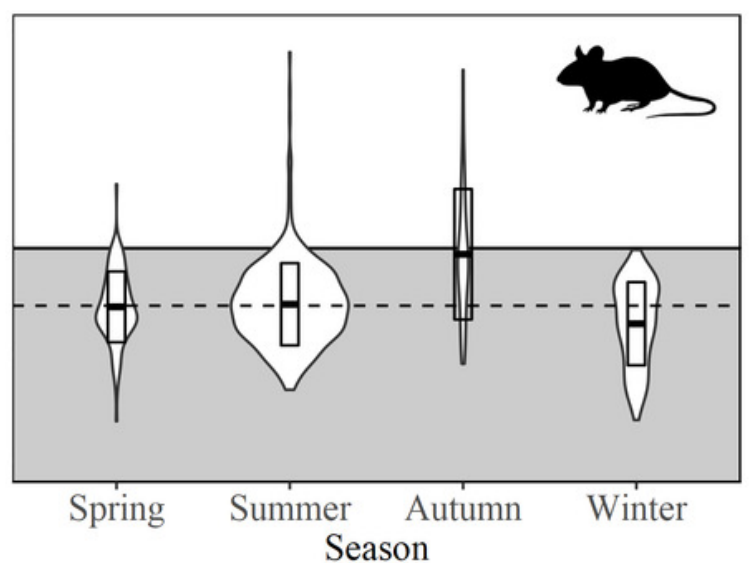




\section{Table $\mathbf{1}$ (on next page)}

Number of remote-sensing camera traps deployed (i.e. 'camera locations') by mammal studies carried out in Northern Ireland between 2013-2016.

Contributory studies were independent, thus methodologies were not standardised; study locations (size, shape) and camera array densities varied considerably. For more information, see the main Methods section. Squirrel surveys were focussed on presence and did not attempt to quantify the effective survey area of all camera placements. 


\begin{tabular}{lrcccc}
\hline Focal species & \multicolumn{1}{c}{ Year } & $\begin{array}{c}\text { Total survey } \\
\text { area }\left(\mathbf{k m}^{2}\right)\end{array}$ & $\begin{array}{c}\text { Active } \\
\text { cameras }\end{array}$ & $\begin{array}{c}\text { Total camera } \\
\text { Deployments } \\
\text { locations }\end{array}$ \\
\hline Deer (D1) & $2013-14$ & 20.00 & 38 & 23 & 255 \\
Deer (D2) & 2015 & 0.05 & 10 & 4 & 40 \\
Deer (D3) & 2015 & 0.02 & 10 & 2 & 20 \\
Deer (D4) & 2015 & 0.04 & 10 & 2 & 20 \\
Deer (D5) & 2015 & 0.05 & 17 & 1 & 17 \\
Deer (D6) & 2015 & 0.02 & 21 & 1 & 21 \\
Hares & $2013-14$ & 17.00 & 20 & 17 & 340 \\
Hares & 2015 & 6.00 & 12 & 6 & 72 \\
Squirrels (S1) & 2014 & $\mathrm{n} / \mathrm{a}$ & 16 & 63 & 63 \\
Squirrels (S2) & 2015 & $\mathrm{n} / \mathrm{a}$ & 65 & 314 & 314 \\
\hline
\end{tabular}




\section{Table 2 (on next page)}

Total number of species detections during camera trap surveys in Northern Ireland from $2013-2016$

Hare $=$ Irish hare (Lepus timidus hibernicus) and European hare (L. europaeus); squirrel = grey squirrel (Sciurus carolinensis) and red squirrel (S. vulgaris). BM = body mass (Jones et al., 2009). Hare and squirrel body mass are given as a mean of the two detected species:

European hare $=3.82 \mathrm{~kg}$; Irish hare $=3.11 \mathrm{~kg}$; grey squirrel $=0.55 \mathrm{~kg}$; red squirrel $=0.33$ $\mathrm{kg}$. Species are ordered according to body mass. 


\begin{tabular}{|c|c|c|c|c|c|c|c|}
\hline \multicolumn{2}{|c|}{ Species } & \multirow[b]{2}{*}{ BM (kg) } & \multicolumn{4}{|c|}{ Season } & \multirow[b]{2}{*}{$\sum$} \\
\hline Common name & Latin name & & Spring & mmer & Autumn & Winter & \\
\hline Fallow deer & Dama dama & 57.00 & 38 & 484 & 61 & 8 & 591 \\
\hline Badger & Meles meles & 11.00 & 618 & 225 & 36 & 68 & 947 \\
\hline Fox & Vulpes vulpes & 4.80 & 198 & 183 & 149 & 115 & 645 \\
\hline Hare & Lepus sp. & 3.46 & 301 & 339 & 105 & 6 & 751 \\
\hline Rabbit & Oryctolagus cuniculus & 1.59 & 492 & 417 & 238 & & 175 \\
\hline Pine marten & Martes martes & 1.30 & 251 & 73 & 356 & 286 & 966 \\
\hline Squirrel & Sciurus sp. & 0.44 & 1,798 & 317 & 462 & 293 & 870 \\
\hline Wood mouse & Apodemus sylvaticus & 0.02 & 449 & 57 & 119 & 191 & 816 \\
\hline
\end{tabular}




\section{Table 3 (on next page)}

Annual and seasonal overlap (\%, with 95\% Confidence Intervals [Cls]) in the activity patterns of five predator-prey pairs.

Animals were detected during camera trap surveys in Northern Ireland between 2013 - 2016. Hare $=$ Irish hare (Lepus timidus hibernicus) and European hare (L. europaeus); squirrel = grey squirrel (Sciurus carolinensis) and red squirrel (S. vulgaris). Few hares were detected during winter. Activity data were resampled 1,000 times per pair, per category, to generate Cls. 


\begin{tabular}{lllllll}
\hline \multicolumn{2}{c}{ Species } & & \multicolumn{4}{c}{ Season } \\
\cline { 1 - 3 } \cline { 5 - 6 } Predator & \multicolumn{1}{c}{ Prey } & Annual & Spring & Summer & Autumn & Winter \\
\hline Fox & Hare & $73(68-77)$ & $75(64-84)$ & $67(60-73)$ & $48(31-52)$ & - \\
Fox & Rabbit & $80(75-83)$ & $89(86-98)$ & $78(71-85)$ & $52(38-55)$ & $51(31-71)$ \\
Fox & Wood mouse & $81(75-87)$ & $78(67-89)$ & $85(81-92)$ & $69(57-74)$ & $68(65-98)$ \\
Marten & Squirrel & $40(33-41)$ & $28(16-30)$ & $54(41-60)$ & $40(32-41)$ & $5(0-5)$ \\
Marten & Wood mouse & $71(64-74)$ & $69(57-82)$ & $71(56-82)$ & $63(52-66)$ & $77(66-93)$ \\
\hline
\end{tabular}




\section{Table 4 (on next page)}

Temporal (dis)associations between activity patterns of five predator-prey pairs.

Lag range and peak lag were calculated using cross-correlation functions (ccfs). $t=\mathrm{t}$ value, where the critical value $(p=0.05, \mathrm{df}=22)=1.72 . r=$ correlation coefficient. Positive values indicate that detections of predators preceded/succeeded those of prey species. Negative values indicate the opposite. Statistical significance is indicated by asterisks, where: * $\leq$ $0.05 ; * * \leq 0.001 ; * * * \leq 0.0001$. 


\begin{tabular}{|c|c|c|c|c|c|c|c|}
\hline \multirow[b]{2}{*}{ Predator } & \multirow[b]{2}{*}{ Prey } & \multirow[b]{2}{*}{ Season } & \multicolumn{2}{|c|}{ Lag (hrs) } & \multirow[b]{2}{*}{$\begin{array}{c}\text { Peak } \\
\text { lag }\end{array}$} & \multirow[b]{2}{*}{$t$} & \multirow[b]{2}{*}{$r$} \\
\hline & & & From & To & & & \\
\hline Fox & Hare & Annual & -4 & 0 & -2 & 4.15 & $0.663 * *$ \\
\hline Fox & Hare & Spring & -2 & 3 & 1 & 3.12 & $-0.554 *$ \\
\hline Fox & Hare & Summer & -5 & 0 & -3 & 3.54 & $0.602 * *$ \\
\hline Fox & Hare & Autumn & -3 & -1 & -3 & 2.08 & $0.405^{*}$ \\
\hline Fox & Rabbit & Annual & -10 & -8 & -9 & 2.13 & $0.413 *$ \\
\hline Fox & Rabbit & Annual & -3 & 1 & -1 & 4.13 & $0.661 * *$ \\
\hline Fox & Rabbit & Annual & 8 & 11 & 10 & 2.10 & $-0.409^{*}$ \\
\hline Fox & Rabbit & Spring & -1 & 2 & 1 & 4.61 & $0.701 * * *$ \\
\hline Fox & Rabbit & Spring & - & - & 11 & 2.14 & $-0.415^{*}$ \\
\hline Fox & Rabbit & Summer & -12 & -9 & -4 & 2.52 & $-0.473 *$ \\
\hline Fox & Rabbit & Summer & -4 & 1 & -1 & 4.06 & $0.654 * *$ \\
\hline Fox & Mouse & Annual & -12 & -10 & -11 & 2.56 & $-0.480 *$ \\
\hline Fox & Wood mouse & Annual & -2 & 3 & 1 & 5.39 & $0.754 * * *$ \\
\hline Fox & Wood mouse & Spring & -2 & 3 & 1 & 3.26 & $0.570 *$ \\
\hline Fox & Wood mouse & Summer & -10 & -9 & -10 & 2.09 & $-0.407 *$ \\
\hline Fox & Wood mouse & Summer & -1 & 1 & 0 & 5.50 & $0.761 * * *$ \\
\hline Fox & Wood mouse & Autumn & 0 & 2 & 2 & 3.04 & $0.544^{*}$ \\
\hline Pine marten & Squirrel & Annual & -12 & -7 & -9 & 2.15 & $0.416^{*}$ \\
\hline Pine marten & Squirrel & Annual & -1 & 4 & 1 & 3.72 & $-0.621 * *$ \\
\hline Pine marten & Squirrel & Spring & -10 & -4 & -6 & 2.50 & $0.470 *$ \\
\hline Pine marten & Squirrel & Spring & 0 & 5 & 1 & 3.76 & $-0.625 * *$ \\
\hline Pine marten & Squirrel & Summer & -4 & -1 & -2 & 2.79 & $-0.512^{*}$ \\
\hline
\end{tabular}




\begin{tabular}{|c|c|c|c|c|c|c|c|}
\hline Pine marten & Squirrel & Summer & - & - & 8 & 2.46 & $0.464^{*}$ \\
\hline Pine marten & Squirrel & Winter & -9 & -7 & -8 & 2.79 & $0.511^{*}$ \\
\hline Pine marten & Squirrel & Winter & -2 & 3 & -1 & 4.18 & $-0.665^{* *}$ \\
\hline Pine marten & Squirrel & Winter & 9 & 11 & 10 & 3.11 & $0.553 *$ \\
\hline Pine marten & Wood mouse & Annual & -1 & 1 & 0 & 2.98 & $0.536^{*}$ \\
\hline Pine marten & Wood mouse & Spring & 7 & 11 & 10 & 2.29 & $-0.440 *$ \\
\hline Pine marten & Wood mouse & Summer & 3 & -2 & -2 & 2.24 & $0.431^{*}$ \\
\hline Pine marten & Wood mouse & Summer & - & - & 8 & 2.46 & $0.464^{*}$ \\
\hline Pine marten & Wood mouse & Winter & 2 & 4 & 3 & 2.73 & $-0.503^{*}$ \\
\hline Pine marten & Wood mouse & Winter & 6 & 7 & 6 & 2.05 & $0.400 *$ \\
\hline
\end{tabular}

